\title{
Alone with our Thoughts: Investigation of Autonomy Supportive Framing as a Driver of Enjoyment During Quiet Time in Solitude
}

\author{
Thuy-vy Nguyen, Ph.D. \\ Durham University \\ Netta Weinstein, Ph.D. \\ University of Reading \\ Edward L.. Deci, Ph.D. \\ University of Rochester
}

This preprint has been accepted at Collabra: Psychology. Please email the lead author Thuyvy Nguyen thuy-vy.nguyen@durham.ac.uk for updated citation of the published manuscript.

\section{Authors' Notes}

Thuy-vy Nguyen is an Assistant Professor in Social Quantitative Psychology at University of Durham, Durham, United Kingdom.

Netta Weinstein is an Associate Professor in Psychology at the School of Psychology and Clinical Language Sciences at University of Reading, Reading, UK.

Edward L. Deci is a Professorial Fellow at the Australian Catholic University, Sydney, Australia; Helen F. \& Fred H. Gowen Professor Emeritus in the Social Sciences at the University of Rochester, Rochester, NY; and Professor of Motivation and Management at the University College of Southeast Norway, Honefoss, Norway.

Correspondence concerning this article should be addressed to Thuy-vy T. Nguyen, Department of Psychology, University of Durham, Durham, United Kingdom DH1 2HX. Contact: thuy-vy.nguyen@durham.ac.uk. 


\begin{abstract}
Sitting alone with one's thoughts could foster a sense of rest and relaxation, yet many find this activity difficult. In two preregistered experiments (Study 1: $n=266$, Study 2: $n=369$ ), we focused on autonomy-supportive and controlling framings of solitude as drivers of motivation for solitude, positive experiences such as enjoyment and relaxation, negative experiences such as frustration and boredom, and negative thoughts like worries and rumination. In Study 1, we found support for one hypothesis that autonomy-supportive instructions to sit alone with thoughts led to greater autonomous motivation for solitude compared to controlling instructions that pressured participants to sit alone. However, the effect of instructions on autonomous motivation was trivial, with a smaller effect observed in Study 2. More importantly, we did not find evidence that our autonomy-supportive instructions meaningfully influenced self-reported measures of participants' experiences with sitting alone with thoughts, nor both self-reported and behavioral measures intention to be in solitude again. Examination of null effects suggested that most differences between autonomy-supportive and controlling-instruction conditions were likely too small to be practically meaningful. However, some null findings in relation to excitement, relaxation, or frustration during sitting alone with thoughts were equivocal and required larger sample sizes to determine whether there was indeed an absence of effect. Consistent with findings reported by Nguyen et al. (2018), participants displayed drops in high-arousal types of affect and increases in low-arousal types of affect. Future research is needed to explore other factors that influence motivation for solitude and lead people to benefit from the regulatory effects of time spent alone.
\end{abstract}




\section{Alone with our Thoughts: Investigation of Autonomy Support as a Driver of Enjoyment During Quiet Time in Solitude}

Solitude benefits emotion regulation (Nguyen et al., 2018), and allows opportunities for people to relax and to be in touch with themselves (Pfeifer et al., 2019). A survey of more than 18,000 people across 134 countries showed that majority of adults saw time alone as an opportunity for rest, particularly when such time was spent on low-key activities like reading, being in nature, listening to music, or doing nothing in particular (Hammond, 2016). An experimental study also showed that daily embracing of solitude reduced the average stress level of the week (Nguyen et al., 2018). In a diary study of mothers, those who pursued more alone time were less likely to report stress and transmit it to their children (Larson \& Gillman, 1999).

Despite these benefits of solitude to daily emotion or stress regulation, spending time alone has its challenge, since the absence of social stimuli often brings people more in tune with their thoughts and inner feelings. Sometimes self-awareness in solitude can be pleasant (Pfeifer \& Wittmann, 2020), but for the most part people generally find sitting with one's thought less enjoyable than having something to do when they are alone (Wilson et al., 2014). This aversiveness of sitting alone with one's thoughts has been demonstrated in a cross-national sample (Buttrick et al., 2018). It is perhaps rather surprising that, as a species which prides itself on reasoning abilities, humans fear being alone with our wandering thoughts and require a certain level of assistance to maintain focus (Alahmadi et al., 2017; Westgate et al., 2017).

The ability to tolerate and even flourish during time spent alone with oneself might differ across individuals depending on how they approach this experience. For example, seeing solitude as beneficial rather than lonely help people gain more regulatory benefits from sitting alone with their thoughts (Rodriguez et al., 2020). This finding is consistent with 
the broader literature that showed time spent alone is more tolerable for those who embrace solitude as a choice rather than an unwanted experience (Lay et al., 2020). From both clinical and developmental perspectives, the capacity to be alone (Winnicott, 1958) - an ability to maintain psychological balance during time spent reflecting on one's inner experiences - has been linked to psychological maturity (Hämäläinen, 1999). Consistently, empirical data has linked the ability to derive positive experiences from solitude to well-being (Thomas \& Azmitia, 2019) and self-esteem (Nguyen et al., 2019).

In recent years, conceptual approaches that explore who derive value from solitude, and when, have incorporated a self-determination theory (Ryan \& Deci, 2017) perspective. Informed by self-determination theory, researchers assert that self-determined or autonomous motivation for solitude - defined as being motivated to be alone for its benefits and enjoyment - is an important predictor of solitary enjoyment (Nguyen et al., 2018; Thomas \& Azmitia, 2019). Yet, the majority of studies demonstrating the role of chosen solitude and autonomous motivation for solitude in facilitating its positive outcomes are correlational (i.e., Lay et al., 2020; Nguyen et al., 2018, 2019; Thomas \& Azmitia, 2019), and cannot speak to the causal effects on autonomous motivation or experiences in solitude. Given how little enthusiasm we seem to have for sitting alone with our thoughts, despite its regulatory benefits, can we reframe people's perception of this activity in ways that allow us to see greater value in, and in turns benefit more from, it?

\section{The Present Research}

The aim of the present research was to examine whether reactions to the challenge of sitting alone with one's thoughts could be influenced by practices that led people to be more autonomously motivated to experience solitude. Informed by self-determination theory, we aimed to increase autonomous motivation for solitude through the use of autonomysupportive and controlling instructions. An autonomy-supportive instruction involves 
language that supports choice (e.g., "it is up to you"), taking an interest in the participant's perspective (e.g., "I understand you might find this experience challenging"), and providing meaningful rationales for any rules or guidelines (e.g., "it is important that...”). This way of providing instructions for an activity has increased students' autonomous motivation for learning (Reeve \& Jang, 2006), even when the learning task is uninteresting (Reeve et al., 2002). In contrast, a controlling instruction uses pressuring language such as "we expect you", "you must", or "you should" to drive action (Vansteenkiste et al., 2005; Weinstein et al., 2017). Such language triggers perceived social pressure (Vansteenkiste et al., 2014), and undermines receivers' self-expression (Barber, 1996; Soenens \& Vansteenkiste, 2010).

Using these motivational framings, we compared the effects of autonomy-supportive versus controlling instructions on several outcomes. The first outcome was participants' autonomous motivation for solitude, operationalized in terms of individuals' reports they were motivated to engage with solitude for its benefits and positive effects rather than due to external influences or obligations. To measure autonomous motivation, we assessed participants' self-reported motivation for solitude (i.e., sitting alone with their thoughts) in the lab. Second, we tested how autonomy-supportive versus controlling instructions influenced participants' experiences with solitude in the lab, and their intention to persist in it when given a second, later opportunity to be alone with their thoughts. Third, we tested whether these two instructions would have different effects on future intention to engage with solitude outside of the lab and the following day.

In Study 1, autonomy-supportive versus controlling instructions were tested against a neutral instruction. Inclusion of a neutral condition allows us to evaluate the effects of the two treatments, autonomy-supportive instructions and controlling instructions, with a standard procedure that does not use any motivational framings. We tested the following hypotheses: 
Autonomous motivation for solitude. Based on previous findings (Vansteenkiste et al., 2005; Weinstein et al., 2017), we predicted that those in the autonomy-supportive instruction condition would display the highest level of relative autonomous motivation for solitude, while those in the neutral condition would display a middle level, and those in the controlling-instruction condition would display the lowest level (Hypothesis 1).

Solitude experience and future intention. Building on the literature linking autonomous motivation for solitude with positive outcomes such as emotional well-being (Chua \& Koestner, 2008) and self-esteem (Nguyen et al., 2018), we predicted that autonomysupportive instructions would lead to greater positive solitary experiences (i.e., enjoyment, relaxation, excitement, likelihood to be in solitude again, desire to be in solitude again) and lower negative solitary experiences (i.e., frustration, boredom, rumination, worries, paranoia) during solitude compared to the neutral and controlling-instruction conditions. We anticipated that the controlling-instruction condition would show the lowest levels of positive experiences and highest levels of negative experiences (Hypothesis 2).

Free-choice behavior. We investigated whether autonomy-supportive versus controlling instructions would influence the extent to which participants engaged in an alternative activity rather than sitting with their thoughts. For this outcome, we used a similar procedure to that used in Wilson et al.'s (2014) Study 10 by instructing participants to be alone with their thoughts, but also allowing them the opportunity to experience an alternative, unattractive activity during a "free-choice period" that followed the solitude period. We predicted that those who received autonomy-supportive instructions would be less likely to choose the unattractive alternative than spending time alone with their thoughts, compared to the neutral and controlling-instruction conditions, whereas those who received controlling instructions would be most likely to select the unattractive alternative (Hypothesis 3). 
End-of-day well-being. We examined whether our manipulation would have prolonged effects outside of the laboratory setting. We predicted that compared to the controlling and neutral conditions, the autonomy-supportive instruction condition would display lower stress and loneliness, and greater relatedness to others, at the end of the day of the lab session (Hypothesis 4).

\section{Exploratory Questions}

Although we did not specify these hypotheses in the preregistration, we investigated whether autonomy-supportive and controlling instructions would have different effects on mood from before to after participants sat alone with their thoughts. Previous research has shown that sitting quietly in solitude (Nguyen et al., 2018; Pfeifer et al., 2019) leads to significant drops in both high-arousal positive (e.g., excited) and high arousal negative (e.g., anxious) affect, whereas low-arousal affects-both positive (e.g., calm) and negative (e.g., sad)-increase. Referred to as the deactivation effect, time spent in solitude dampens arousal levels and gives rise to low-arousal states such as relaxation, if positive, and loneliness, if negative. In this study, we explored whether receiving different motivational framings would determine whether participants gained the positive, calming effect of solitude or suffered from its lonely consequence. We predicted that autonomy-supportive instructions would lead to increases in low-arousal positive affect, whereas controlling instructions would lead to increased low-arousal negative affect.

\section{Study 1}

\section{Method}

\section{Recruitment Method}

Participants were recruited from the participant pool of a psychology department at a private university in the United States. Study 1 data collection was completed between February, 2017 and May, 2017. Per the preregistered plan, we planned to recruit 246 
participants to detect a small effect size of $f=.20$ (equivalent to $\eta^{2}=.039$ ) at $80 \%$ power for an $F$-test with three conditions using one-way ANOVA. In the first week of data collection, we learned that the audio recording of the controlling instruction was too quiet. We created a new audio file to correct this issue. Participants in the controlling-instruction condition recruited before this error was corrected were excluded; this exclusion criterion was described in our preregistration plan, as the pre-registration was written after data collection (but before data analysis).

Time slots were posted weekly based on research assistants' availability. By the last week of the Spring semester of 2017, 246 participants had signed up for the posted time slots. However, we continued to recruit for another week in case of no-shows or cancellations. This approach allowed us to ensure we would achieve our target sample size within the timeframe in which the participant pool was open. But it resulted in a larger sample size than was preregistered. No data analysis was performed before data collection stopped.

\section{Participants}

A total of 266 participants between the ages of 18 and 25 years $(M=2.10$ years, $S D=$ 1.35; 194 females, 68 males, 2 who selected "other", and 3 who did not report their gender) took part in the study. The sample consisted of 98 Caucasian participants, 97 Asians or Asian American participants, 18 Black participants, 22 Hispanic or Latino participants, 15 identified as mixed races or other races, and 16 did not report ethnicity.

\section{Study Manipulation}

Participants were randomized to listen to one of the three instructions that had been pre-recorded by the same female experimenter. Condition assignment was fully random using the Randomizer algorithm on Qualtrics. For the controlling instructions, we used explicitly demanding language such as "you must" or "you should", and stressed that the experimenter "expects" the participant to sit alone without engaging in any other activities. For the 
autonomy-supportive instruction, we used wording such as "I invite you to" and "you can", and we emphasized that different people might have different reactions to this activity so that participants could feel free to explore their feelings with a sense of choice. Finally, participants in the neutral condition were instructed to undertake the same activity, but the instructions simply used the word "please" in delivering the instructions without any of the motivational language described above. These instructions have been shown to change perceptions of autonomy support in previous studies (Vansteenkiste et al., 2005; Weinstein et al., 2018). In Appendix A, we included the protocol that was used to train research assistants, including the actual wording of all the instructions delivered to the participants.

\section{Procedure}

An advertisement of our study, named "Solitude Study", was posted on the university's research and participant management website (SONA). This advert informed participants that the purpose of the study was to understand how solitude affected experiences. In the consent form, it was explained that participants would listen to different instructions and complete several activities during the lab session. The research assistant was not present in the room when participants engaged in each activity described below.

Manipulation phase. After consenting, participants completed a short questionnaire measuring their current affect. To ensure that participants would not engage in any activity while spending time alone in the lab, all belongings, including backpacks, digital devices such as computers, phones, or smartwatches, were left outside of the room. Following this, participants listened to an audio recording of either autonomy-supportive, controlling, or neutral instructions to spend time alone in the room without any activity available to them. Audio recordings were delivered on the lab iPad when the research assistant was not present in the room, so that the research assistant was not aware of condition assignment. The screen 
on the iPad was locked so that the participants could not exit out of the survey for the entirety of the study.

Alone with thought phase. After listening to the instructions, participants were given a brief manipulation-check measure, and also a scale that assessed their autonomous motivation for solitude. Both of those measures were administered prior to the actual solitude task to prevent retrospective bias after the event had taken place. Then, participants spent time alone in the room with no other activity for 15 minutes, though they were not told how long they would be left on their own. After 15 minutes, they completed a questionnaire that assessed their experience with the activity, intention to engage with the activity again, and once again, their affect.

Alone with alternative activity. After they spent 15 minutes alone with their thoughts, the research assistant introduced the participants to another activity. Participants were given a bucket of approximately 1500 blue and red golf pencils, which had been emptied from their original boxes and collated in the bucket (www.gpencil.com; Item\#: P405B). Participants were instructed to organize pencils by color back into empty pencil boxes in an orderly fashion. This activity was selected because it was banal and repetitive. Participants did this task for 5 minutes, and then reported their enjoyment for the activity.

Free-choice period. After having been exposed to both being alone with their thoughts, and being alone with an alternative activity, participants were asked to remain in the room alone for 10 more minutes. At this point, the research assistant instructed participants that they could either sit alone with their thoughts once again, or they could sort more pencils. Participants' enjoyment for this period was recorded at the end of the session.

Aside from the outcome measures reported in this paper, three measures of stress, loneliness, and social connectedness were also sent to participants at the end of the day of the 
lab session to determine whether condition assignment in the lab changed end of the day reports.

\section{Transparency Statement}

All audio recordings, study materials, and analytical scripts are shared on the Open Science Framework (https://osf.io/fszfw/?view_only=6770b48f22f545feb721c517fb2048f3). The study's hypotheses and analytical plans were registered after data collection but prior to data analyses

(https://osf.io/gfyj9/register/5730e99a9ad5a102c5745a8a?view only=d1f6d5235d7f4248b4c $\underline{5 e 82908 f 95350)}$.

\section{Measures}

\section{Preregistered Measures}

Manipulation check. Six items assessed participants' perceptions that the experimenter's communication style supported their basic psychological needs. Those items were adapted from the nine-item measure by La Guardia et al. (2000). Although we were mainly interested in autonomy support, self-determination theory suggests that autonomy support is most effective when the receiver also perceived that their feelings are cared for (i.e., relatedness support), and they are capable of carrying out tasks and requests (i.e., competence support; Su \& Reeve, 2011). Therefore, participants responded to items measuring each type of support: autonomy support (e.g., "Did the experimenter help you feel that you had choice in the experience you were about to undertake?"); relatedness support (e.g., "Did you feel that the experimenter cared about you?"); and competence support (e.g., “Did the experimenter help you feel capable and effective in what you were about to do?"). We added three items (i.e., "Did you feel that the experimenter explained the instruction well?", "Did you find the experimenter attractive?", "Did you find the experimenter 
friendly?") to mask the purpose of the measure. These items were rated on 7-point scales from 1 (not at all) to 7 (definitely so).

Autonomous motivation for solitude. This variable was assessed using eight items from a previous measure of autonomous motivation for solitude (i.e., Nguyen et al., 2018). Example items are "I am about to undertake this experience..." "because it sounds like something I would enjoy", and "Because I feel like I should do it even though I am not entirely up for it" (reverse coded). These items were rated on 7-point scales $(\alpha=.81)$.

Solitude experience and future intention. After sitting alone with their thoughts, pencil-sorting, and the free-choice period, participants responded to five items with the stem: "I found the experience", followed by the adjectives: "enjoyable", "exciting", "boring", “frustrating", "relaxing”. For being alone with thoughts, items were measured on 7-point scales, whereas for the pencil-sorting and free-choice periods, items were measured on 9point scales.

Additionally, only for the first alone period (i.e., sitting alone with thoughts), we included three items to assess the extent to which participants experienced negative thoughts. Those items started with the stem: "I spent the last period by myself", which was followed by the phrases: "Thinking about bothersome event or problem that I experienced recently/in the past" (i.e., rumination), "Worrying" (i.e., worry), "Being stressed out by the thought that someone could be watching me" (i.e., paranoia). Items were measured on 9-point scales.

Two items were used to assess participants' intention to engage again with the experience that they had in the lab. Those items were: "How likely are you to seek out time to sit alone with your thoughts and feelings, similar to what you just experienced, in the next two weeks?" and "How much would you like to experience again what you just did in this lab session (aka sitting alone with your thoughts and feelings)?” 
Free-choice behavior. To measure how much participant engaged with the alternative activity when spending time alone during free-choice period, the research assistant counted the number of pencils sorted at the beginning and the end of the 10-minute freechoice period. To do this, each pencil box was marked with numbered lines; the number associated with each line indicated the rows of pencils that had been sorted into a particular box (see Appendix A). The research assistant was able to quickly count the number of pencil boxes that had been completed and the number of pencil rows that had been sorted in those boxes that were incomplete when the research assistant entered the room. Each box of pencils originally held 144 pencils, which were organized into 8 rows (18 pencils per row). Based on these numbers, to calculate the number of pencils sorted at the beginning and at the end of the 10-minute free-choice period, we used the following formula:

Total count $=($ number of completed boxes $* 144)+($ number of rows in incomplete boxes * 18)

Engagement with this alternative activity when alone was measured in terms of the difference between the total count at the beginning and the end of the free-choice period.

End-of-day well-being. To explore the effects of condition assignment on well-being throughout the remainder of the day, we included well-being measures at the beginning of the lab session (i.e., pre-solitude) and again in a survey that was sent to participants at the end of the day of the lab session (i.e., end-of-day). We measured three variables: perceived stress, loneliness, and relatedness satisfaction, and asked participants to think about the items described below in relation to that evening and up to the moment they received the survey. All three variables were measured on 7-point scales; this is a deviation from previous validated versions of the scales and was intended to maintain consistency within response scales across measures in the study. 
Perceived stress. Participants completed the 4-item Perceived Stress Scale (Wartig et al., 2013), including items such as "I feel like difficulties are piling up so high that I cannot overcome them", or "I feel confident about my ability to handle my personal problems" (presolitude: $\alpha=.80$; end-of-day: $\alpha=.81$ ).

Loneliness was measured using the 3-item UCLA Loneliness Scale (Hughes et al., 2004), including the following items: "I feel like I lack companionship", "I feel left out", and "I feel isolated from others around me" (pre-solitude: $\alpha=.84$; end-of-day: $\alpha=.84$ ).

Relatedness satisfaction was measured using six items measuring relatedness satisfaction subscale from the Basic Psychological Need Satisfaction (La Guardia et al., 2000), including, "I really like the people I interacted with", "I pretty much kept to myself and did not have a lot of social contacts" (pre-solitude: $\alpha=.73$; end-of-day: $\alpha=.77$ ).

\section{Exploratory Measures}

Affect. Before and after participants spent time sitting alone with their thoughts, they responded to emotion items taken from previous research (De Dreu et al., 2008; Nguyen et al., 2018) to assess high-arousal positive affect (i.e., happy, elated, excited; Before: $\alpha=.78$, After: $\alpha=.73$ ), high-arousal negative affect (i.e., afraid, worried, angry; Before: $\alpha=.64$, After: $\alpha=.74$ ), low-arousal positive affect (i.e., calm, relaxed, at ease; Before: $\alpha=.87$, After: $\alpha=.87$ ), and low-arousal negative affect (i.e., bored, depressed, lonely, sad, drained; Before: $\alpha=.77$, After: $\alpha=.77)$.

\section{Exclusion Criteria}

We did not register exclusion criteria in our preregistration. However, after examining the data for free-choice behavior, we identified five participants for which the research assistants miscounted the numbers of pencils the second time, yielding negative values. Because negative values for this variable were not meaningful, we coded those values as missing data. Further, after the free-choice period, we included one item that assessed 
compliance with the instruction by asking the participant: "During the last alone period, were you engaging in any other activities other than sorting pencils or sitting with yourself?". We will report analyses on free-choice behavior with and without those who answered 'yes' to this question.

\section{Statistical Analyses}

All analyses were conducted using R program (Version 1.3.1056). To test Hypotheses $1-3$, we used the 'aov' function and performed planned contrast analysis using the 't.test' function in the R package 'stats' (Version 3.6.3). We used 'ci.smd' function in the R package 'MBESS' (Version 4.8.0) to calculate Cohen's $d$ effect sizes and the 95\% confidence intervals. Finally, we tested Hypothesis 4 using the 'lm' function from the 'stats' package (Version 3.6.3).

\section{Results}

\section{Manipulation Check}

As shown in Table 1, we found an effect of the manipulation on participants' perception that the experimenter supported their autonomy for sitting alone with their thoughts $\left(F(2,261)=19.18, p<.001, \eta^{2}=.13\right)$. Consistent with self-determination theory, there was also an effect of condition on perception of relatedness $(F(2,263)=21.30, p<$ $\left..001, \eta^{2}=.14\right)$ and competence $\left(F(2,262)=6.69, p=.001, \eta^{2}=.05\right)$ need support. We present the planned contrasts in Table 2. Overall, planned contrasts showed that the differences between autonomy-supportive instruction and both neutral $(d=0.68$, CI 95\% $[0.36,1.00], t(137.05)=4.33, p<.001)$ and controlling $(d=0.90$, CI 95\% $[0.61,1.20]$, $t(172.42)=6.24, p<.001)$ instructions yielded large and significant effects. On the other hand, the difference between the controlling and neutral instructions was smaller and not statistically significant $(d=-0.28$, CI 95\% [-0.58, 0.02], $t(172.25)=-1.83, p=.068)$. 
Autonomous motivation for solitude. Condition predicted autonomous motivation for solitude $\left(F(2,260)=4.68, p=.010, \eta^{2}=.03\right)$ in the expected direction: autonomysupportive instruction yielded the highest level, neutral instructions yielded an intermediate level, and controlling instructions yielded the lowest level of autonomous motivation. Planned contrasts in Table 2 showed that the difference between autonomy-supportive instruction and controlling instruction reached statistical significance $(d=0.43$, CI $95 \%$ $[0.14,0.72], t(186.72)=2.98, p=.003)$. The difference between controlling and neutral instructions was not significant $(d=-0.30$, CI 95\% $[-0.60,0.00], t(162.47)=-1.96, p=.051)$, and the difference between autonomy-supportive and neutral instructions was also not significant $(d=0.13$, CI 95\% $[-0.18,0.44], t(151.3)=0.82, p=.413)$. These findings did not support our hypothesis that autonomy-supportive instructions would yield greater level of autonomous motivation when compared to neutral instructions, or that neutral instructions would yield greater autonomous motivation when compared to controlling instructions. We only observed a statistically significant difference between autonomy-supportive and controlling instructions predicting relative autonomous motivation.

Solitude experience and future intention. Contrary to Hypothesis 2, we did not find a significant effect of condition on composite scores of all items assessing participants' experiences during their time spent alone with their thoughts $\left(F(2,260)=0.35, p=.707, \eta^{2}=\right.$ .00). ANOVA tests predicting individual items also did not yield significant condition effect (see Table 2). There was also not a significant condition effect on participants' negative thoughts during time spent alone with their thoughts $\left(F(2,262)=0.10, p=.904, \eta^{2}=.00\right)$, and an additional test predicting individual items did not yield significant effects.

Finally, we did not find evidence that the three conditions differed on self-reported likelihood of participants sitting alone with their thoughts in the future $(F(2,262)=0.06, p=$ $\left..939, \eta^{2}=.00\right)$, nor the desire to be in solitude again $\left(F(2,261)=0.57, p=.568, \eta^{2}=.00\right)$. 
Free-choice behavior. Contrary to Hypothesis 3, we did not find an effect of condition on the number of pencils sorted during the free-choice period $(F(2,256)=1.54, p=$ $\left..226, \eta^{2}=.01\right)$. We conducted the analysis without those participants who had said they were engaging in activities other than sorting pencils or sitting with themselves during free-choice period $(n=13)$; doing this did not change the finding. The average scores of additional pencils sorted in each of the three conditions (see Table 1) were partly consistent with the direction predicted in Hypothesis 3. The controlling-instruction condition yielded the highest number of pencils sorted during the free-choice period. However, participants in the autonomy-supportive instruction condition did not sort the smallest number of additional pencils.

End-of-day well-being. To test Hypothesis 4, we predicted that the autonomysupportive instruction condition would show lower end-of-day stress and loneliness, and greater relatedness to others. We conducted regression analyses with dummy codes to compare autonomy-supportive instructions with neutral instructions (Dum 1) and controlling instructions with neutral instructions (Dum 2), accounting for levels of well-being assessed prior to participants sitting alone with their thoughts. We did not find significant effects of autonomy-supportive or controlling instructions, compared to neutral instructions, predicting perceived stress (Dum 1: $B=-.14, S E . B=.14, t(247)=-1.01, p=.312 ;$ Dum 2: $B=-.05$, $S E . B=.14, t(247)=-0.33, p=.743)$, loneliness (Dum 1: $B=-.17, S E . B=.16, t(247)=-1.08$, $p=.280 ;$ Dum 2: $B=-.03, S E . B=.16, t(247)=-0.20, p=.841)$. The effect of the autonomysupportive versus neutral instructions predicting end-of-day levels of relatedness was also not significant (Dum $1: B=.26, S E . B=.13, t(249)=1.97, p=.050)$, and we also did not find an effect of controlling versus neutral instructions predicting end-of-day levels of relatedness (Dum 2: $B=.05, S E . B=.13, t(249)=0.36, p=.717$ ). Therefore, we did not find evidence 
that receiving either autonomy-supportive or controlling instructions significantly affected end-of-day well-being when compared with neutral instructions.

\section{Exploratory Analyses}

We looked at changes in four forms of affect: high-arousal positive affect, higharousal negative affect, low-arousal positive affect, and low-arousal negative affect. We conducted 3 (Condition: autonomy-supportive, neutral, controlling (Between-Subjects)) x 2 (Time: pre vs. post lab session (Within-Subjects)) ANOVAs to investigate whether changes from before to after being alone with thoughts were moderated by condition. Omnibus $F$ tests did not show significant condition-by-time interactions on any of the affective outcomes. The between-subject effects of condition were also not significant, indicating that levels of affect averaged over both assessments did not differ significantly across three conditions (Table 3).

Previous studies by Nguyen et al. (2018) showed that sitting alone with one's thoughts for 15 minutes led to decreases in high-arousal positive and negative affect, a phenomenon named the deactivation effect (i.e., studies 1-3). Consistent with that finding, we observed decreases of both high-arousal negative $\left(F(1,524)=6.87, p=.009, \eta^{2}=.01\right)$ and higharousal positive affect $\left(F(1,523)=16.66, p<.001, \eta^{2}=.03\right)$; these changes were not moderated by condition (Table 4).

Further, Nguyen et al. (2018) reported increases of low-arousal positive and negative affect after people sat alone with their thoughts or read (i.e., Studies 2-3). In the present study, we also found increased low-arousal positive affect across conditions $(F(2,523)=$ 19.77, $\left.p<.001, \eta^{2}=.04\right)$; this change was not moderated by condition. Unlike Nguyen et al. (2018), we did not find an increase in low-arousal negative affect. An omnibus $F$ test showed that the change in low-arousal negative affect was not significant $(F(2,521)=1.02, p=.313$, $\left.\eta^{2}=.00\right)$; this (lack of an) effect was not moderated by condition (Table 4$)$

\section{Study 2}


In Study 1, we found statistically significant differences between autonomysupportive and controlling-instruction conditions on perception of autonomy support from the experimenter and self-reported relative autonomous motivation for solitude. The differences between these two conditions in relation to the neutral-instruction condition suggested that it was the controlling instruction that undermined participants' autonomous motivation for solitude, whereas we did not find evidence that autonomy-supportive instruction had positive impact on this outcome. The wide confidence interval around the effect size of the controlling and neutral-instruction condition comparison predicting autonomous motivation for solitude suggested that further research is needed to confirm whether this is a true effect.

The difference between autonomy-supportive and controlling-instruction conditions was consistent with previous literature that contrasted choiceful and enforced solitude (Galanaki, 2004; Lay et al., 2020; Nguyen et al., 2018). Here, we demonstrated this effect in an experimental design. Because we wanted to focus on an effect in which we had more confidence and increase statistical power to detect this effect, in Study 2 we directly contrasted autonomy-supportive and controlling-instruction conditions. As such, Study 2 was a direct replication of Study 1, with the removal of the neutral-instruction condition. We accepted as a cost of this decision that we could no longer determine which of the two experimental conditions drove observed differences. We preregistered hypotheses regarding effects of condition on the following outcomes:

Changes in affect. First, we wanted to investigate the effects of autonomy-supportive versus controlling instructions on change in affect from before to after solitude. In Study 1, we conducted exploratory analyses to investigate the condition-by-time interactions and did not find evidence that condition moderated these changes in affect. However, one previous finding by Nguyen et al. (2018; Study 4) suggested that those with higher autonomous motivation for solitude experienced more low-arousal positive affect and less low-arousal 
negative affect than those with lower autonomous motivation for solitude. In the 2018 study, autonomous motivation was treated as an individual difference and was not manipulated. In Study 1, we manipulated the instructions for being alone with thoughts and found a difference between autonomy-supportive and controlling-instruction conditions on autonomous motivation for solitude. However, this effect did not translate to different changes in low-arousal positive and negative affect as suggested in Nguyen et al. (2018; Study 4). This could be a false negative, so we planned to confirm the condition-by-time interactions again. Specifically, we made the following predictions for low-arousal positive and negative affect: 1) Both types of low-arousal affect would increase after solitude, and 2) there would be condition-by-time interactions such that the manipulation would lead to a greater increase in low-arousal positive affect and a smaller increase in low-arousal negative affect in the autonomy-supportive instruction condition, compared to controlling-instruction condition. For high-arousal positive and negative affect, we only predicted a within-subject decrease for both conditions (i.e., no interaction).

Free-choice behavior. The second hypothesis concerned the comparison between autonomy-supportive and controlling-instruction conditions on free-choice behavior. Free choice behavior was operationalized as the extent to which participants spent more time sitting alone with thoughts or engaged with an alternative activity made available to them in the lab. We did not find a significant difference between the two conditions on this variable in Study 1, but the means were in the predicted direction: those in the controlling-instruction condition sorted more extra pencils into boxes than those in the autonomy-supportive instruction condition. Therefore, we tested the same comparison in Study 2 using a larger sample.

Free-choice solitude experience. The third hypothesis concerned the comparison between autonomy-supportive and controlling-instruction conditions predicting experiences 
during the free-choice period. In Study 1, we did not find a significant difference between the two conditions for participants' experiences during the alone with thought period. The mean difference between these two conditions during the free-choice period was in the predicted direction but was not statistically significant $(d=0.26$, CI 95\% $[-0.02,0.55], t(185.58)=$ $1.80, p=.073)$. We sought to confirm this difference in Study 2 and predicted that those in the autonomy-supportive instruction condition would experience greater enjoyment, excitement, and relaxation than those in the controlling-instruction condition.

End-of-day relatedness. The fourth hypothesis concerned the effect of autonomysupportive versus controlling instructions on participants' levels of relatedness at the end of the day. The effect of autonomy-supportive instructions (versus neutral instructions) on dayend relatedness in Study 1 was in the predicted direction but did not reach statistical significance. We sought to confirm this effect and predicted that, compared to controlling instructions, autonomy-supportive instructions would lead to greater relatedness at the end of the day.

Future engagement with solitude. The fifth and final hypothesis concerned the effect of autonomy-supportive versus controlling instructions on participants' later engagement with solitude after the lab session. This new variable was not included in Study 1. We predicted that participants who received autonomy-supportive instructions would be more likely to engage in solitude later than those who received controlling instructions.

\section{Method}

\section{Recruitment Method}

Study 2 was conducted between October, 2017 and May, 2018. We preregistered a sample size of 352 to detect a medium effect size of $d=0.30$ at $\alpha=.05$ with .80 power. To account for cancellations or no-shows, we created 450 time slots on the undergraduate participant recruitment platform. 


\section{Participants}

By the end of the recruitment period, we obtained a sample of 369 participants between the ages of 18 and 28 years $(M=20.09$ years, $S D=1.36 ; 258$ females, 109 males, 1 chose "others", and 1 did not report their gender). Of these, 147 identified as Caucasian, 133 identified as Asian or Pacific Island, 20 identified as Black, 38 as Hispanic or Latino, and 20 identified as mixed races or other races (11 did not report ethnicity).

\section{Transparency Statements}

All audio recordings, study materials, and analytical scripts are shared on OSF (link: https://osf.io/w67gu/?view_only=40179f7fefff49cf8fdc0a18d8d1c9bf), and the study's hypotheses and analytic plan were preregistered after data collection but prior to data analyses (link: https://osf.io/6fs72/?view_only=89a68da27c2647a59d3ea4ccebaacde9).

\section{Measures}

Measures were the same as those used in Study 1. The only one measure added to this study was one item that asked participants: "After the lab session today, did you spend time sitting with yourself, similar to what you have experienced in the lab?". The participants were given the following options to respond: 0 = "not at all", 1 = "yes, for less than a minute", 2 = "yes, for 1-5 minutes", 3 = "yes, for 5-10 minutes", 4 = "yes, for 10-15 minutes", and 5 = "yes, for more than 15 minutes". We created two indices: for one, we entered the variable into the analysis as an ordinal variable with six discrete categories ranging from 0 to 5 , and for the other, we created a binary variable by recoding values ranging from 1 through 5 into one category indicating whether participants had spent any time engaging in solitude again after the lab session.

\section{Exclusion Criteria}

The only preregistered exclusion criterion was that we would only include those participants who provided complete data. We deviated from preregistered plan because we 
also treated negative values for the free-choice behavior as missing data. Further, after the free-choice period, we included one item that assessed compliance with the instructions by asking the participant: "During the last alone period, were you engaging in any other activities other than sorting pencils or sitting with yourself?". We will report analyses on the free-choice behavior variable with and without those who answered yes to this question.

\section{Statistical Analyses}

All analyses were conducted using R program (Version 1.3.1056). To test Hypothesis 1 , we used the 'aov' function and performed paired $t$-tests using the 't.test' function in the $\mathrm{R}$ package 'stats' (Version 3.6.3). We extracted the means and standard deviations of affect measures before and after the first period of being alone with thoughts, then used 'ci.sm' function in the R package 'MBESS' (Version 4.8.0) to calculate Cohen's d effect sizes of pre-post in-lab solitude experience and the $95 \%$ confidence intervals.

To test Hypotheses 2 and 3, we performed independent two-way $t$-tests using the 't.test' function from the same package 'stats'. We tested Hypothesis 4 using the 'Im' function and Hypothesis 5 using the 'chisq.test' function from the 'stats' package. In a later section at the end of the Results section of Study 2, we will use the 'forestplot' package (version 2.0) to compare all effect sizes of non-significant results in Study 1 and Study 2 to evaluate consistencies across two studies.

\section{Results}

We followed the same analytic approaches for all the variables that were taken from Study 1 . We will only present the findings of preregistered hypotheses below. All analyses that were not part of the Study 2 preregistration are included in the Supplementary Materials (see table $\mathrm{S} 1)$.

\section{Manipulation Check}


As can be seen in Table 4, there was a significant difference in perceived autonomy support between autonomy-supportive and controlling-instruction conditions in the expected direction $(d=0.65$, CI 95\% $[0.44,0.86], t(347.73)=6.28, p<.001)$. Consistent with findings of Study 1 , the difference was also significant for relatedness support $(d=1.09$, CI 95\% $[0.87,1.31], t(351.43)=1.45, p<.001)$ and competence support $(d=0.37$, CI $95 \%[0.17$, $0.58], t(365.14)=3.58, p<.001)$.

\section{Preregistered Analyses}

Changes in affect. Hypothesis 1 predicted both main effects for within-subject changes from before to after sitting alone with one's thoughts - decreases in high-arousal types of affect and increases in low-arousal types of affect - as well as condition-by-time interactions for only low-arousal types of affect. Only our predictions for the within-subject main effects of time were supported, which is also consistent with the main findings of Nguyen et al (2018). Specifically, we found significant within-subject decreases on both high-arousal positive affect $\left(F(1,729)=28.63, p<.001, \eta^{2}=.04\right)$, and high-arousal negative $\operatorname{affect}\left(F(1,730)=14.77, p<.001, \eta^{2}=.02\right)$. We also found significant within-subject increases of both low-arousal positive affect $\left(F(1,730)=3.71, p<.001, \eta^{2}=.04\right)$ and lowarousal negative affect $\left(F(1,731)=4.00, p=.046, \eta^{2}=.01\right)$. We did not find significant condition-by-time interactions for any types of affect (see Table 5).

These results replicated the main findings of Nguyen et al. (2018) that high-arousal affective states dropped, and low-arousal affective states rose, after solitude. Though Nguyen et al.'s Study 4 found that individual differences in autonomous motivation for solitude moderated the effect of solitude on low-arousal affect, we did not extend this finding to show that supporting autonomy through the manipulation we used would result in such changes. Therefore, Hypothesis 1 was only partly supported, such that we only found evidence supporting predictions for within-subject changes but not for condition-by-time interactions. 
Free-choice behavior. Hypothesis 2 predicted a condition effect on free-choice behavior (sorting pencils rather than sitting alone with one's thoughts). We did not find support for this hypothesis. The difference between autonomy-supportive and controllinginstruction conditions was in the predicted direction but was not significant $(d=-0.12$, CI $95 \%[-0.32,0.09], t(359.24)=-1.13, p=.257)($ see Table 5$)$. We conducted the analysis excluding participants who reported engaging in activities other than sorting pencils or sitting with themselves during free-choice period $(n=15)$; this did not change the finding.

Free-choice solitude experience. Hypothesis 3 predicted that those who received autonomy-supportive instructions would have more positive experiences during the freechoice period when they were left alone in the room to freely choose between sitting with their thoughts or engaging in an alternative activity. We did not find support for this hypothesis. There was no condition effect on composite scores of all items assessing participants' experiences with being alone with their thoughts $(d=0.06$, CI 95\% $[-0.15$, $0.26], t(363.74)=0.54, p=.593)$. T-tests on individual items also yielded no condition effect (Table 6).

End-of-day relatedness. Hypothesis 4 predicted that those who received autonomysupportive instructions in the lab would experience greater levels of relatedness compared to those who received controlling instructions. We did not find support for this hypothesis. Regression analysis showed no condition effect on end-of-day relatedness $(B=-.17, S E . B=$ $.11, t(300)=-1.60, p=.110)$, controlling for participants' levels of relatedness prior to solitude experience (Table 7a).

Future engagement with solitude. Hypothesis 5 predicted that those who received autonomy-supportive instructions in the lab would be more likely to engage in a similar solitude experience outside of the lab, when compared to those who received controlling instructions. Of the sample, 307 participants responded to the question asking whether they 
had engaged in similar solitude after the lab session. Treating future engagement with solitude as an ordinal variable with 6 discrete categories, regression analysis did not yield significant condition effect $(B=.15, S E . B=.16, t(305)=0.96, p=.338)$ (Table 7a).

When we recode this variable into binary measure of whether participants engaged in solitude after the lab session at all, we observed 71 out of $151(47 \%)$ participants in the autonomy-supportive instruction condition indicated they spent some time in a similar solitude experience after the lab. On the other hand, 62 out of $156(40 \%)$ participants in the controlling-instruction condition said they did. A chi-square test also did not yield significant effect $\left(\chi^{2}=1.37, p=.242\right)$. Therefore, we did not find support for Hypothesis 5 (Table 7b).

\section{Evaluation of Effects Across Studies}

Across both studies, most of the results on outcomes measured during the lab session and outside of the lab yielded null effects. Results on outcomes measured outside of the lab session were trivial and inconsistent in directions of the observed effects. In this section, we will evaluate the effect sizes of the differences between autonomy-supportive and controlling-instruction conditions on in-lab outcomes across two studies.

In Figure 1, we presented forest plots of Cohen's $d$ s representing the differences between these two conditions on all the outcomes measured in Studies 1 and 2. We compared effect sizes observed to an interval null between -0.30 and 0.30 ; that is, we determined that an effect size smaller than 0.30 either in favor of the autonomy-supportive or controllinginstruction condition would not be practically meaningful. The interval null between -0.30 and 0.30 was an arbitrary choice, as there was no clear reference for which effect sizes to expect from the previous literature for our manipulation. This interval null was also not a mathematical choice, as we entirely based our decision of the interval null on what the first author subjectively considered to be practically meaningful. Given that our studies used a rather subtle manipulation, we did not expect to get an effect size as large as .40 or .50 , but 
we considered .20 too small to be practically meaningful. We settled for .30 as the largeenough effect size to aim for for this type of manipulation. Based on a meta-analysis by Ntoumanis et al. (2021), the smallest effect size of SDT-based interventions was also estimated to be around .30 .

As seen in Figure 1, most of the effect sizes obtained in Study 1 have 95\% confidence intervals that contain values falling inside the null interval. However, because of the wide confidence intervals, it is difficult to draw meaningful conclusions about these null effects. We observed clearer patterns in Study 2, with smaller confidence intervals that allowed some level of precision to make meaningful conclusions about the null effects. Particularly, confidence intervals of the effects on paranoid thoughts in solitude, likelihood to be in solitude again, enjoyment with pencil-sorting, and enjoyment with free-choice period sat entirely inside the null interval. We determined those effect sizes too small to be considered practically meaningful.

Other null effects that have values both inside and outside of the -0.30 and 0.30 range were inconclusive. That means we could not determine whether there was truly no effect of instructions on those outcomes, or whether our sample was not sufficiently powered to detect an effect. There were some meaningful patterns that can guide future research; Figure 1 showed that the effects on positive outcomes favor the autonomy-supportive instruction condition and the effects on negative outcomes favor the controlling-instruction condition. For outcomes like "exciting", "relaxing", "frustrating", and extra pencils during free-choice period which yielded null results, we would require a larger sample size to draw meaningful conclusions around whether there was indeed an absence of effect.

We conducted the same procedure to evaluate the effects of our manipulation on endof-day measures and illustrated observed effect sizes in Figure 2. In Study 1, we investigated the effects of condition on ratings of perceived stress, loneliness, and relatedness at the end of 
the day that the participants participated in the lab session. In Study 2, we only included ratings of relatedness and whether participants pursued solitude outside of the lab in the surveys sent out at the end of the day. We controlled for baseline levels of those variables and obtained the beta $(\beta)$ coefficients that represent the effects of the autonomy-supportive instruction relative to the neutral instruction, and of the controlling instruction relative to the neutral instruction (see Table 3). To compare the results obtained in Study 1 with those of Study 2 , we performed an additional analysis to obtain the $\beta$ coefficient that represents the effect of the autonomy-supportive instruction on end-of-day measures, relative to the controlling instruction (see Table $S 2$ in Supplementary Materials). Again, we compared observed standardized coefficients to an interval null between -0.30 and 0.30 . As seen in Figure 2, most coefficients obtained across two studies have $95 \%$ confidence intervals that contain values falling inside the null interval. Similar to the results for in-lab measures, the coefficients obtained in Study 1 have wider confidence intervals compared to those in Study 2 , which revealed clearer that the effects of our manipulation on end-of-day measures were likely too small to be practically meaningful. This suggests to us that while our manipulation might have some observable effects in the lab, the effects might not be prolonged and extended to participants' experiences at the end of the day.

\section{Discussion}

The present research tested several self-determination theory hypotheses that supporting people's autonomy for solitude would increase their autonomous motivation for sitting alone with their thoughts and subsequently help them enjoy the experience better. Previous research has suggested that the experience of sitting alone with one's thoughts is a particularly challenging and unwelcomed experience for many (Buttrick et al., 2018; Wilson et al., 2014). In both studies, we developed different instructions that either supported autonomy for time spent alone or pressured participants to be alone with controlling 
language. Our manipulation assessing perceived autonomy support suggested that the instructions were effective. Despite that, we did not find evidence that autonomy-supportive or controlling instructions administered in a laboratory setting impacted participants' experiences, behavior, or their intention to experience time alone with their thoughts again.

In Study 1, we found support for Hypothesis 1 that different instructions changed participants' perceived autonomous motivation for sitting alone with their thoughts. We found that the difference was only significant when comparing the autonomy-supportive versus controlling instructions, but neither set of instructions was particularly effective when compared to the neutral instruction. We found the difference between autonomy-supportive and controlling instructions to be statistically significant in Study 2, and in the same direction. This finding suggests that motivation for sitting alone with thoughts might only differ between situations that are perceived to be clearly supportive of autonomy or clearly controlling. However, the effect size was much smaller in Study 2, indicating that the effect of our particular instructions on autonomous motivation for solitude would require future replications with larger samples to ensure that this effect is true.

We did not find support for hypotheses in relation to the effect of the autonomysupporting manipulation on participants' experiences when sitting alone with their thoughts, their intention and desire to be in solitude again, the well-being benefits they gained from it, nor their actual subsequent engagement with solitude. We tested these hypotheses using both self-reported and behavioral measures. First, we asked participants to report on their experience immediately after the solitude experience. Second, we offered them an alternative, rather banal and boring task, and then had them sit alone again to see whether they would prefer engaging with the alternative task or sit alone with their thoughts. Third, we distributed another survey after the lab session to ask about participants' end-of-day well-being and whether they engaged in a similar solitude experience again. Overall, we did not find 
evidence that receiving autonomy-supportive nor controlling instructions changed these outcomes.

In Study 2, we preregistered that after sitting alone with their thoughts, participants would display drops in high-arousal types of affect, similar to the findings reported by Nguyen et al. (2018). We found support for this hypothesis. We also preregistered that the autonomy-supportive instruction condition would show larger increases in low-arousal positive affect but smaller increases in low-arousal negative affect compared to the controlling-instruction condition. We did not find support for this hypothesis. Our participants generally experienced increases in both low-arousal positive affect (e.g., feeling calm) and low-arousal negative affect when sitting alone with their thoughts, and these increases were not moderated by conditions as predicted. Patterns of effect sizes for changes in all types of affect were consistent with the patterns reported in Nguyen et al. (2018) metaanalyses, indicating that the deactivation effect of solitude was at play in all conditions.

Nguyen et al. (2018) argued that drops in high-arousal types of affect could be the regulatory benefits of solitude. However, that does not mean these benefits are recognized or appreciated by our participants. In the present research, when offered another opportunity to do it again, only a small portion of participants chose to spend time during the free-choice period sitting alone with their thoughts, while the majority instead engaged in the banal, unattractive activity of sorting pencils. This happened regardless of which instructions participants received. That is, in both studies we did not find evidence for our preregistered hypothesis that autonomy supportive or controlling instructions would affect this choice. We explored a potential explanation in the Supplementary Materials (see Table S3), that the participants could have found the pencil-sorting task more interesting and enjoyable and therefore the majority of them would prefer this task over being alone with their thoughts. We did not find support for this explanation. Overall, we did not find significant differences 
between ratings of enjoyment for the pencil-sorting task compared to sitting alone with one's thoughts.

Examination of effect sizes and their confidence intervals across both studies allowed us to draw meaningful conclusions about some of the null effects. We determined that the differences between autonomy-supportive and controlling-instruction conditions on paranoid thoughts in solitude, likelihood to be in solitude again, enjoyment with pencil-sorting, and enjoyment with free-choice period, were too small to be considered practically meaningful. Additionally, the effects of instructions on participants' ratings of their well-being and likelihood of pursuing similar solitude experience outside of the lab were also not likely to be meaningful. This became clearer in Study 2 when the effects of autonomy-supportive versus controlling instructions on end-of-day measures have smaller confidence intervals which fall completely inside the interval null. The other null effects were inconclusive as they had $95 \%$ confidence intervals that include values both inside and outside of the range between -0.30 and 0.30 - an interval that we used to determine whether effects were too small to be considered meaningful. Replications using larger samples are required to determine the presence or absence of meaningful effects. From our results, we suggest that future studies that attempt to use the same or a modified version of our manipulation to focus on achieving meaningful effects on in-lab measures first, before attempting to investigating the effects on more distal outcomes. Further, we suggest that future manipulation also incorporate other self-determination theory techniques, such as identifying barriers to solitary enjoyment (e.g., negative social norms that associate solitude with loneliness) or expressing empathy around the challenges of solitude. These techniques have been showed to enhance the effectiveness of self-determination theory-informed interventions in health domain (Ntoumanis et al., 2021). 
Additionally, there are several limitations to our study procedure. First, our study was advertised as a "Solitude study". It is possible this title attracted participants who were more open to experiencing solitude because they found it a positive experience. It is equally possible that those who felt they struggled with excessive solitude felt inclined to take part. While our data cannot speak to this issue, it may be useful to consider in future research. Given that the word "solitude" might carry different meanings (Galanaki, 2004; Wang, 2006), we suggest that future researchers studying these topics advertise their study using a more generic name.

Another limitation is the lack of precision in our calculation of extra pencils sorted during the free-choice period as a proxy to measure participants' engagement with an alternative, unattractive, activity instead of sitting alone with thoughts. To save time, our research assistants did not count the actual number of pencils that participants sorted into boxes, but instead read the lines marked on the boxes that indicate how many rows of pencils had been sorted. Then we applied an equation that assumed one row approximates to 18 pencils and one box approximates to 144 pencils. In fact, it is possible that participants could have fitted less than or more than 18 pencils into one row, or less than or more than 144 per box. Therefore, this measure was not precise, and furthermore was prone to mistakes, as evidenced by a number of cases that resulted in negative numbers. For future research, we recommended a different banal activity that would be less prone to those errors. This activity should satisfy the following criteria: 1) It should be repetitive and present no novel stimulation, 2) Its self-reported ratings on enjoyment should be comparable to those of sitting alone with thoughts. Some pilot testing might be necessary to identify such a task and align it with the specific population under study.

Finally, because our studies followed a structured protocol in the lab, it is difficult to generalize this work to real-life settings. While an experimental design in the lab increases 
internal validity, the limitations of our studies lie in their lack of ecological validity and generalizability. To address this limitation, we have two recommendations. First, we suggest that future research could use a similar design to that used in Nguyen et al. (2018), which combined the use of a diary design and a switching-replications experimental design (Shadish et al., 2002). This methodology would allow us to observe the effect of autonomysupportive versus controlling instructions on people's experiences with sitting alone with their thoughts in their natural environment, and to investigate situational factors (e.g., living alone or sharing with others) that might interact with daily motivation for this activity. Further, by exposing participants to autonomy-supportive versus controlling instructions for a week instead of on a single occasion, researchers could observe the cumulative effect of instructions on motivation over time. Moving the study outside of the laboratory setting also makes it possible to recruit samples other than undergraduate students. Particularly, this would allow future researchers to also investigate whether different motivational framings for solitude could have varied effects on different age groups and people with different living arrangements (e.g., living in shared household versus living alone). Second, we suggest researchers explore other factors that could interfere with participants' engagement with solitude or their autonomous motivation for it, such as their pre-existing preference for solitude (Burger, 1995; Cramer \& Lake, 1998), or history of experienced ostracism (Ren et al., 2020). As such, an effective intervention might involve considering individual differences and situational factors in combination, which requires large samples and clearly stated hypotheses of interactions between these variables.

Overall, since embracing the opportunity to sit quietly in solitude has downstream regulatory benefits (e.g., Nguyen et al., 2018; Pfeifer et al., 2019; Rodriguez et al., 2020), it would be worthwhile to investigate the reasons that it may be difficult to sit alone with one's own thoughts. This research is particularly relevant now, when the rise of media technologies 
and increasing pressure to be productive make it easy for us to be preoccupied with deadlines, responsibilities, and the distracting draw of our smartphones. Many studies have begun to highlight the benefits of solitude for mood regulation (Nguyen et al., 2018) and rest (BBC, 2016), so it is important to define contextual factors that could improve the quality of this experience. 


\section{References}

Alahmadi, S., Buttrick, N. R., Gilbert, D. T., Hardin, A. M., Westgate, E. C., \& Wilson, T. D. (2017). You can do it if you really try: The effects of motivation on thinking for pleasure. Motivation and Emotion, 41(5), 545-561. https://doi.org/10.1007/s11031-017$9625-7$

Barber, B. K. (1996). Parental psychological control: Revisiting a neglected construct. Child Development, 67(6), 3296-3319. https://doi.org/10.1111/j.1467-8624.1996.tb01915.x

Burger, J. M. (1995). Individual differences in preference for solitude. Journal of Research in Personality, 29(1). https://doi.org/https://doi.org/10.1006/jrpe.1995.1005

Buttrick, N., Choi, H., Wilson, T. D., Oishi, S., Boker, S. M., Gilbert, D. T., Alper, S., Aveyard, M., Cheong, W., Colic, M. V., Dalgar, I., Dogulu, C., Karabati, S., Kim, E., Kneževic, G., Komiya, A., Laclé, C. O., Lage, C. A., Lazarevic, L. B., ... Wilks, D. C. (2018). Cross-cultural consistency and relativity in the enjoyment of thinking Versus doing. Journal of Personality and Social Psychology. https://doi.org/10.1037/pspp0000198

Chua, S. N., \& Koestner, R. (2008). A self-determination theory perspective on the role of autonomy in solitary behavior. Journal of Social Psychology, 148(5), 645-648. https://doi.org/10.3200/SOCP.148.5.645-648

Cramer, K. M., \& Lake, R. P. (1998). The preference for solitude scale: Psychometric properties and factor structure. Personality and Individual Differences, 24(2), 193-199. https://doi.org/10.1016/S0191-8869(97)00167-0

De Dreu, C. K. W., Baas, M., \& Nijstad, B. A. (2008). Hedonic tone and activation level in the mood-creativity link: Toward a dual pathway to creativity model. Journal of Personality and Social Psychology, 94(5), 739-756. https://doi.org/10.1037/00223514.94.5.739 
Galanaki, E. (2004). Are children able to distinguish among the concepts of aloneness, loneliness, and solitude? International Journal of Behavioral Development, 28(5), 435443. https://doi.org/10.1080/01650250444000153

Hämäläinen, O. (1999). Some considerations on the capacity to be alone. Scandinavian Psychoanalytic Review, 22(1), 33-47. https://doi.org/10.1080/01062301.1999.10592690

Hammond, C. (2016). How being alone may be the key to rest. BBC Radio 4. https://www.bbc.co.uk/news/magazine-37444982

La Guardia, J. G., Ryan, R. M., Couchman, C. E., \& Deci, E. L. (2000). Within-person variation in security of attachment: A self-determination theory perspective on attachment, need fulfillment, and well-being. Journal of Personality and Social Psychology, 79(3), 367-384. https://doi.org/10.1037/0022-3514.79.3.367

Larson, R. W., \& Gillman, S. (1999). Transmission of emotions in the daily interactions of single-mother families. Journal of Marriage and the Family, 61(1), 21. https://doi.org/10.2307/353880

Lay, J. C., Pauly, T., Graf, P., Mahmood, A., \& Hoppmann, C. A. (2020). Choosing solitude: Age differences in situational and affective correlates of solitude-seeking in midlife and older adulthood. Journals of Gerontology - Series B Psychological Sciences and Social Sciences, 75(3), 483-493. https://doi.org/10.1093/geronb/gby044

Nguyen, T. T., Ryan, R. M., \& Deci, E. L. (2018). Solitude as an approach to affective selfregulation. Personality and Social Psychology Bulletin, 44(1), 92-106. https://doi.org/10.1177/0146167217733073

Nguyen, T. T., Werner, K. M., \& Soenens, B. (2019). Embracing me-time: Motivation for solitude during transition to college. Motivation and Emotion, 43(4), 571-591. https://doi.org/10.1007/s11031-019-09759-9

Ntoumanis, N., Ng, J. Y. Y., Prestwich, A., Quested, E., Hancox, J. E., Thøgersen-Ntoumani, 
C., Deci, E. L., Ryan, R. M., Lonsdale, C., \& Williams, G. C. (2021). A meta-analysis of self-determination theory-informed intervention studies in the health domain: effects on motivation, health behavior, physical, and psychological health. Health Psychology Review, 15(2), 214-244. https://doi.org/10.1080/17437199.2020.1718529

Pfeifer, E., Geyer, N., Storch, F., \& Wittmann, M. (2019). “Just Think”-Students feel significantly more relaxed, less aroused, and in a better mood after a period of silence alone in a room. Psych, 1(1), 343-352. https://doi.org/10.3390/psych1010024

Pfeifer, E., \& Wittmann, M. (2020). Waiting, thinking, and feeling: variations in the perception of time during silence. Frontiers in Psychology, 11(April), 1-11. https://doi.org/10.3389/fpsyg.2020.00602

Reeve, J., \& Jang, H. (2006). What teachers say and do to support students' autonomy during a learning activity. Journal of Educational Psychology, 98(1), 209-218. https://doi.org/10.1037/0022-0663.98.1.209

Reeve, J., Jang, H., Hardre, P., \& Omura, M. (2002). Providing a rationale in an autonomysupportive way as a strategy to motivate others during an uninteresting activity. Motivation and Emotion, 26(3), 183-207. https://doi.org/10.1023/A:1021711629417

Ren, D., Wesselmann, E. D., \& van Beest, I. (2020). Seeking Solitude After Being Ostracized: A Replication and Beyond. Personality and Social Psychology Bulletin. https://doi.org/10.1177/0146167220928238

Rodriguez, M., Bellet, B. W., \& McNally, R. J. (2020). Reframing time spent alone: Reappraisal buffers the emotional effects of isolation. Cognitive Therapy and Research, 0123456789. https://doi.org/10.1007/s10608-020-10128-x

Shadish, W. R., Cook, T. D., \& Campbell, D. T. (2002). Experimental and designs for generalized causal Inference. In Experimental and quasi-experimental design for causual inference. Houghton Mifflin Company. 
Soenens, B., \& Vansteenkiste, M. (2010). A theoretical upgrade of the concept of parental psychological control: Proposing new insights on the basis of self-determination theory. Developmental Review, 30(1), 74-99. https://doi.org/10.1016/j.dr.2009.11.001

Su, Y. L., \& Reeve, J. (2011). A Meta-analysis of the effectiveness of intervention programs designed to support autonomy. Educational Psychology Review, 23(1), 159-188. https://doi.org/10.1007/s10648-010-9142-7

Thomas, V., \& Azmitia, M. (2019). Motivation matters: Development and validation of the Motivation for Solitude Scale - Short Form (MSS-SF). Journal of Adolescence, 70(November), 33-42. https://doi.org/10.1016/j.adolescence.2018.11.004

Vansteenkiste, M., Simons, J., Lens, W., Soenens, B., \& Matos, L. (2005). Examining the motivational impact of intrinsic versus extrinsic goal framing and autonomy-supportive versus internally controlling communication style on early adolescents' academic achievement. Child Development, 76(2), 483-501. https://doi.org/10.1111/j.14678624.2005.00858.x

Vansteenkiste, M., Soenens, B., Van Petegem, S., \& Duriez, B. (2014). Longitudinal associations between adolescent perceived degree and style of parental prohibition and internalization and defiance. Developmental Psychology, 50(1), 229-236.

https://doi.org/10.1037/a0032972

Wang, Y. (2006). Culture and solitude: Meaning and significance of being alone. University of Massachusetts, Amherst.

Weinstein, N., Zougkou, K., \& Paulmann, S. (2017). You "have" to hear this: Using tone of voice to motivate others. Journal of Experimental Psychology: Human Perception and Performance. https://doi.org/https://doi.org/10.1037/Fxhp0000502

Westgate, E. C., Wilson, T. D., \& Gilbert, D. T. (2017). With a little help for our thoughts: Making it easier to think for pleasure. Emotion, 17(5), 828-839. 
https://doi.org/10.1037/emo0000278

Wilson, T. D., Reinhard, D. A., Westgate, E. C., Gilbert, D. T., Ellerbeck, N., Hahn, C., Brown, C. L., \& Shaked, A. (2014). Just think: The challenges of the disengaged mind. Science, 345(6192), 75-77. https://doi.org/10.1126/science.1250830

Winnicott, D. W. (1958). Capacity to be alone. The International Journal of Psycho-Analysis, $39,416$. 


\section{Appendix A}

STEP 1: SIGN-IN. Make sure participants sign-in their names when they enter the lab.

- Open survey page. The first thing you see will be the Information letter. Turn on guided access.

\section{STEP 2: INFORMATION LETTER AND SURVEY 1.}

- Administer information letter and survey 1:

"Here is the information letter. Please read this and if you agree to participate, please click "next" to fill out the first survey. You will be listening to the instruction on the iPad. Just follow the instruction and let me know when you need me."

\section{*Leave the room*}

\section{STEP 3: VERBAL MANIPULATION delivered on IPAD}

Participants come out the $1^{\text {st }}$ time. At this time, collect participants' belongings, including books, backpacks, electronic devices, and a watch if they have one on them. Ask them to repeat the instructions back to you in their own words.

* Leave the room*

15-minute SOLITUDE

Buzz subjects after 15-minutes

Wait for subjects to come out to notify you.

Participants come out the $2^{\text {nd }}$ time. At this time, give the instruction for the pencil-sorting task. Make sure you give the instruction before entering your Experimenter's code and click next.

$$
\text { *Leave the room* }
$$

\section{STEP 4: PENCIL SORTING TASK INSTRUCTION:}

"The next task is a pencil-sorting task. For this task, please take ONLY the blue and the red pencils out of this bin, and sort them into two separate boxes. Make sure all pencils are put in the same direction and fit all the pencils in one row before you move on to the next row. There are several boxes here for you to fill in with pencils, Make sure you fill each box all the way to the top, THEN move on to the next box. Do this for a few minutes, then you will hear another signal. When you hear the signal, go ahead and finish the row that you are working on and then proceed to fill out Survey Number 3. Do you have any questions about this part of the experiment?"

*Leave the room* 
5-minute PENCIL SORTING

Buzz subjects after 5-minutes

Wait for subjects to come out to notify you.

Participants come out the $3^{\text {rd }}$ time. Count pencils in the boxes. Take all the time you need. THEN, give the instruction for the free-choice period. Make sure you give the instruction before entering your Experimenter's code and click next.

- Start with the numbers of boxes of pencils that the subjects have completed, separately for red and blue.

- $\quad$ Then count the number of rows of pencils in the incomplete boxes.

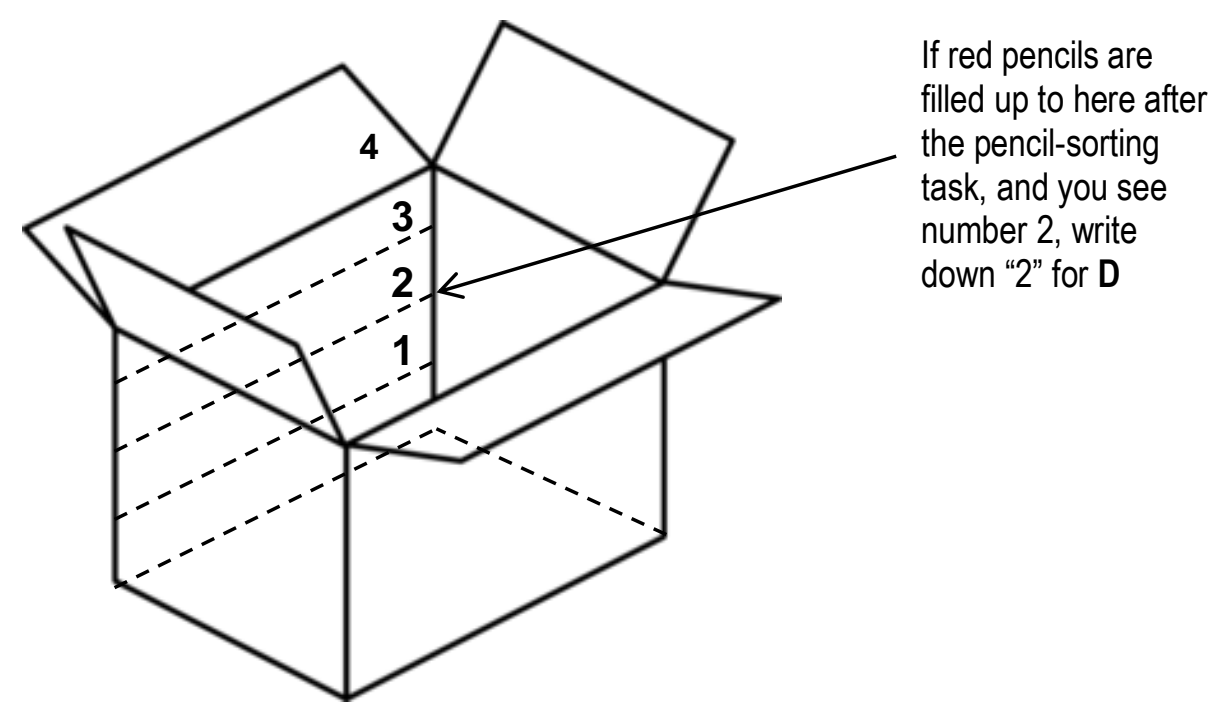

\section{STEP 6: FREE CHOICE INSTRUCTION:}

"So there will be another survey I will ask you to fill out, but before we move on, you will be alone again for 10 minutes. Please remain in your seat and stay awake. This time you can take a few minutes to sit alone with yourself and rest. Or, you can occupy your time by sorting more pencils if you like. It doesn't matter which of these two things you choose to do. The purpose of this session is for you to spend the time you are alone in the way that you prefer between the two activities you have experienced in this session. So I ask that you not do anything else besides either sitting alone with yourself or sorting pencils, and also not touch anything else in the room so the room will be the same for the next participant. After 10 minutes you will hear a signal again, and at that time, please fill out Survey Number 4. Do you have any questions about this part of the experiment?"

*Experimenter left the room*

10-minute FREE CHOICE

Buzz subjects after 10-minutes

Wait for subjects to come out to notify you. 
Participants come out the $4^{\text {th }}$ time. Count pencils in the boxes, including the ones that have been filled during the pencil-sorting period. Take all the time you need.

\section{STEP 7: DEBRIEFING}

- Ask the participant the following questions:

"What did you think about all the instructions for this study?

Did you feel that you understood what you were asked to do and performed all the parts as instructed?"

- Do not forget the reminders!

"Please do not talk about this experiment with anyone else. We maintain confidentiality of your data. And there are some contact persons listed on the SONA posting of this study if you have any questions. There will be one more survey sent out at the end of today. It is very short and takes only 3 minutes to complete. Please fill it out to receive full credits for the study." 


\section{Funding Statement}

A grant from the European Research Council (851890; SOAR) supported Netta Weinstein. The funders had no role in study design, data analysis, decision to publish, or preparation of the article. 


\section{Tables}

\section{Table 1}

Means and Standard Deviations of all Measured Variables, Omnibus F Tests and Effect Sizes (Study 1)

\begin{tabular}{|c|c|c|c|c|c|c|c|}
\hline & & $\begin{array}{l}\text { Autonomy- } \\
\text { supportive } \\
(\mathrm{n}=88)\end{array}$ & $\begin{array}{c}\text { Controlling } \\
(\mathrm{n}=104)\end{array}$ & $\begin{array}{l}\text { Neutral } \\
(\mathrm{n}=74)\end{array}$ & $F(\mathrm{df})$ & $p$ & $\begin{array}{c}\text { Eta } \\
\text { squared }\end{array}$ \\
\hline \multirow[t]{2}{*}{ Perceived autonomy support } & $M$ & 6.02 & 4.96 & 5.31 & 19.18 & .000 & .13 \\
\hline & $S D$ & 0.89 & 1.42 & 1.14 & $(2,261)$ & & \\
\hline \multirow[t]{2}{*}{ Perceived relatedness support } & $M$ & 5.61 & 4.55 & 5.07 & 21.30 & .000 & .14 \\
\hline & $S D$ & 0.99 & 1.21 & 1.12 & $(2,263)$ & & \\
\hline \multirow[t]{2}{*}{ Perceived competence support } & $M$ & 6.09 & 5.62 & 5.83 & 6.69 & .001 & .05 \\
\hline & $S D$ & 0.77 & 0.94 & 0.88 & $(2,262)$ & & \\
\hline \multirow[t]{2}{*}{ Autonomous motivation } & $M$ & 5.07 & 4.64 & 4.95 & 4.68 & .010 & .03 \\
\hline & $S D$ & 0.94 & 1.07 & 1.01 & $(2,260)$ & & \\
\hline \multirow[t]{2}{*}{ Enjoy being alone with thoughts } & $M$ & 4.31 & 4.18 & 4.22 & 0.35 & .707 & .00 \\
\hline & $S D$ & 1.09 & 1.11 & 1.09 & $(2,260)$ & & \\
\hline \multirow[t]{2}{*}{ Enjoyable } & $M$ & 4.14 & 3.80 & 4.00 & 0.99 & .374 & .01 \\
\hline & $S D$ & 1.59 & 1.77 & 1.69 & $(2,261)$ & & \\
\hline \multirow[t]{2}{*}{ Exciting } & $M$ & 2.17 & 2.01 & 1.86 & 1.34 & .263 & .01 \\
\hline & $S D$ & 1.24 & 1.19 & 1.13 & $(2,261)$ & & \\
\hline \multirow[t]{2}{*}{ Relaxing } & $M$ & 5.01 & 4.89 & 5.03 & 0.20 & .818 & .00 \\
\hline & $S D$ & 1.60 & 1.50 & 1.61 & $(2,262)$ & & \\
\hline \multirow[t]{2}{*}{ Boring } & $M$ & 3.63 & 3.71 & 3.80 & 0.17 & .846 & .00 \\
\hline & $S D$ & 1.84 & 1.77 & 1.82 & $(2,262)$ & & \\
\hline \multirow{2}{*}{ Frujstrating } & $M$ & 2.13 & 1.99 & 1.85 & .83 & .438 & .01 \\
\hline & $S D$ & 1.52 & 1.29 & 1.24 & $(2,262)$ & & \\
\hline \multirow[t]{2}{*}{ Negative thoughts } & $M$ & 1.96 & 1.91 & 1.95 & 0.10 & .904 & .00 \\
\hline & $S D$ & 0.71 & 0.72 & 0.77 & $(2,262)$ & & \\
\hline \multirow[t]{2}{*}{ Ruminate } & $M$ & 2.26 & 2.13 & 2.28 & 0.49 & .616 & .00 \\
\hline & $S D$ & 1.08 & 1.11 & 1.20 & $(2,262)$ & & \\
\hline \multirow[t]{2}{*}{ Worry } & $M$ & 1.94 & 2.01 & 1.89 & 0.28 & .757 & .00 \\
\hline & $S D$ & 1.07 & 1.07 & 1.01 & $(2,262)$ & & \\
\hline \multirow[t]{2}{*}{ Paranoid } & $M$ & 1.67 & 1.60 & 1.68 & 0.27 & .764 & .00 \\
\hline & $S D$ & 0.86 & 0.70 & 0.89 & $(2,262)$ & & \\
\hline \multirow[t]{2}{*}{ Likelihood to be in solitude again } & $M$ & 4.97 & 5.06 & 4.93 & 0.06 & .939 & .00 \\
\hline & $S D$ & 2.53 & 2.25 & 2.72 & $(2,262)$ & & \\
\hline \multirow[t]{2}{*}{ Desire to be in solitude again } & $M$ & 5.15 & 5.49 & 5.43 & 0.57 & .568 & .00 \\
\hline & $S D$ & 2.36 & 2.12 & 2.38 & $(2,261)$ & & \\
\hline \multirow[t]{2}{*}{ Enjoy sorting pencils } & $M$ & 5.73 & 5.49 & 5.56 & 0.59 & .553 & .00 \\
\hline & $S D$ & 1.63 & 1.57 & 1.49 & $(2,261)$ & & \\
\hline \multirow[t]{2}{*}{ Enjoy free-choice } & $M$ & 6.04 & 5.67 & 5.95 & 1.77 & .172 & .01 \\
\hline & $S D$ & 1.34 & 1.55 & 1.38 & $(2,257)$ & & \\
\hline \multirow[t]{2}{*}{ Extra pencils during free-choice } & $M$ & 172.76 & 197.65 & 163.97 & 1.54 & .226 & .01 \\
\hline & $S D$ & 126.93 & 13.40 & 146.71 & $(2,256)$ & & \\
\hline
\end{tabular}


Table 2.

Standardised Pairwise Comparisons (Cohen's d) Between Conditions (Study 1)

\begin{tabular}{|c|c|c|c|c|c|c|c|c|c|}
\hline & \multicolumn{3}{|c|}{$\begin{array}{c}\text { Autonomy-supportive - } \\
\text { Controlling }\end{array}$} & \multicolumn{3}{|c|}{ Controlling - Neutral } & \multicolumn{3}{|c|}{$\begin{array}{c}\text { Autonomy-supportive - } \\
\text { Neutral }\end{array}$} \\
\hline & $t$ & $p$ & $d$ & $t$ & $p$ & $d$ & $t$ & $p$ & $d$ \\
\hline $\begin{array}{l}\text { Perceived } \\
\text { autonomy support }\end{array}$ & 6.24 & .000 & $\begin{array}{c}.90 \\
{[.61,1.20]}\end{array}$ & -1.83 & .068 & $\begin{array}{c}-.28 \\
{[-.58, .02]}\end{array}$ & 4.33 & .000 & $\begin{array}{c}.68 \\
{[.36,1.00]}\end{array}$ \\
\hline $\begin{array}{l}\text { Perceived } \\
\text { relatedness support }\end{array}$ & 6.63 & .000 & $\begin{array}{c}.96 \\
{[.66,1.26]}\end{array}$ & -2.92 & .004 & $\begin{array}{c}-.44 \\
{[-.75,-.14]}\end{array}$ & 3.23 & .002 & $\begin{array}{c}.51 \\
{[.19, .82]}\end{array}$ \\
\hline $\begin{array}{l}\text { Perceived } \\
\text { competence support }\end{array}$ & 3.73 & .000 & $\begin{array}{l}.54 \\
{[.25, .83]}\end{array}$ & -1.51 & .132 & {$[-.53, .07]$} & 1.93 & .056 & $\begin{array}{c}.30 \\
{[-.01, .61]}\end{array}$ \\
\hline $\begin{array}{l}\text { Autonomous } \\
\text { motivation }\end{array}$ & 2.98 & .003 & $\begin{array}{c}.43 \\
{[.14, .72]}\end{array}$ & -1.96 & .051 & $\begin{array}{c}-.30 \\
{[-.60, .00]}\end{array}$ & 0.82 & .413 & $\begin{array}{c}.13 \\
{[-.18, .44]}\end{array}$ \\
\hline $\begin{array}{l}\text { Enjoy being alone } \\
\text { with thoughts }\end{array}$ & 0.82 & .411 & $\begin{array}{c}.12 \\
{[-.16, .40]}\end{array}$ & -0.26 & .793 & $\begin{array}{c}-.04 \\
{[-.34, .26]}\end{array}$ & 0.51 & .611 & $\begin{array}{c}.08 \\
{[-.23, .39]}\end{array}$ \\
\hline Enjoyable & 1.40 & .163 & $\begin{array}{c}.20 \\
{[-.08, .49]}\end{array}$ & -0.78 & .439 & $\begin{array}{c}-.12 \\
{[-.42, .18]}\end{array}$ & 0.53 & .596 & $\begin{array}{c}.08 \\
{[-.23, .39]}\end{array}$ \\
\hline Exciting & 0.92 & .360 & $\begin{array}{c}.13 \\
{[-.15, .42]}\end{array}$ & 0.83 & .409 & $\begin{array}{c}.13 \\
{[-.17, .42]}\end{array}$ & 1.65 & .102 & $\begin{array}{c}.26 \\
{[-.05, .57]}\end{array}$ \\
\hline Relaxing & 0.52 & .605 & $\begin{array}{c}.08 \\
{[-.21, .36]}\end{array}$ & -0.56 & .578 & $\begin{array}{c}-.08 \\
{[-.38, .21]}\end{array}$ & -0.06 & .951 & $\begin{array}{c}-.01 \\
{[-.32, .30]}\end{array}$ \\
\hline Boring & -0.30 & .763 & $\begin{array}{c}-.04 \\
{[-.24, .33]}\end{array}$ & -0.31 & .755 & $\begin{array}{c}-.05 \\
{[-.25, .35]}\end{array}$ & -0.57 & .569 & $\begin{array}{c}-.09 \\
{[-.22, .40]}\end{array}$ \\
\hline Frustrating & 0.66 & .510 & $\begin{array}{c}.10 \\
{[-.38, .19]}\end{array}$ & 0.73 & .468 & {$[-.41, .19]$} & 1.27 & .206 & $\begin{array}{c}.20 \\
{[-.51, .11]}\end{array}$ \\
\hline Negative thoughts & 0.43 & .670 & $\begin{array}{c}.06 \\
{[-.22, .35]}\end{array}$ & -0.33 & .745 & $\begin{array}{c}-.05 \\
{[-.35, .25]}\end{array}$ & 0.06 & .950 & $\begin{array}{c}.01 \\
{[-.3, .32]}\end{array}$ \\
\hline Ruminate & 0.82 & .415 & $\begin{array}{c}.12 \\
{[-.17, .40]}\end{array}$ & -0.84 & .400 & $\begin{array}{c}-.13 \\
{[-.43, .17]}\end{array}$ & -0.11 & .915 & $\begin{array}{c}-.02 \\
{[-.33, .29]}\end{array}$ \\
\hline Worry & -0.43 & .666 & $\begin{array}{c}-.06 \\
{[-.35, .22]}\end{array}$ & 0.75 & .456 & $\begin{array}{c}.11 \\
{[-.18, .41]}\end{array}$ & 0.31 & .759 & $\begin{array}{c}.05 \\
{[-.26, .36]}\end{array}$ \\
\hline Paranoid & 0.61 & .541 & $\begin{array}{c}.09 \\
{[-.20, .37]}\end{array}$ & -0.64 & .525 & $\begin{array}{c}-.10 \\
{[-.40, .20]}\end{array}$ & -0.06 & .948 & $\begin{array}{c}-.01 \\
{[-.32, .30]}\end{array}$ \\
\hline $\begin{array}{l}\text { Likelihood to do it } \\
\text { again }\end{array}$ & -0.26 & .792 & $\begin{array}{c}-.04 \\
{[-.32, .25]}\end{array}$ & 0.33 & .745 & $\begin{array}{c}.05 \\
{[-.25, .35]}\end{array}$ & 0.08 & .937 & $\begin{array}{c}.01 \\
{[-.30, .32]}\end{array}$ \\
\hline Desire to do it again & -1.02 & .307 & $\begin{array}{c}-.15 \\
{[-.43, .14]}\end{array}$ & 0.15 & .879 & $\begin{array}{c}.02 \\
{[-.27, .32]}\end{array}$ & -0.76 & .451 & $\begin{array}{c}-.12 \\
{[-.43, .19]}\end{array}$ \\
\hline $\begin{array}{l}\text { Enjoy sorting } \\
\text { pencils }\end{array}$ & 1.05 & .294 & $\begin{array}{c}.15 \\
{[-.13, .44]}\end{array}$ & -0.32 & .751 & $\begin{array}{c}-.05 \\
{[-.35, .25]}\end{array}$ & 0.70 & .486 & $\begin{array}{c}.11 \\
{[-.20, .42]}\end{array}$ \\
\hline Enjoy free-choice & 1.80 & .073 & $\begin{array}{c}.26 \\
{[-.02, .55]}\end{array}$ & -1.26 & .209 & $\begin{array}{c}-.19 \\
{[-.49, .11]}\end{array}$ & 0.45 & .656 & $\begin{array}{c}.07 \\
{[-.24, .38]}\end{array}$ \\
\hline $\begin{array}{l}\text { Extra pencils during } \\
\text { free-choice }\end{array}$ & -1.31 & .191 & $\begin{array}{c}-.19 \\
{[-.47, .09]}\end{array}$ & 1.57 & .118 & $\begin{array}{c}.24 \\
{[-.06, .54]}\end{array}$ & 0.40 & .693 & $\begin{array}{c}.06 \\
{[-.25, .37]}\end{array}$ \\
\hline
\end{tabular}




\section{Table 3}

Regression Analyses Examining the Effects of Autonomy Supportive and Controlling Instructions on End-ofDay Well-Being

\begin{tabular}{|c|c|c|c|c|c|c|}
\hline & $B$ & SE.B & $\beta$ & $95 \% C I(\beta)$ & $t$ & $p$ \\
\hline & \multicolumn{6}{|c|}{ End-of-day stress } \\
\hline (Intercept) & 67 & .19 & .05 & {$[-.11, .21]$} & 3.60 & $<.001$ \\
\hline Pre-solitude stress & .77 & .05 & .73 & {$[.64, .82]$} & 16.78 & $<.001$ \\
\hline Dum 1 (Autonomy-supportive vs. Neutral) & -.14 & .14 & -.11 & {$[-.33, .11]$} & -1.01 & .312 \\
\hline \multirow[t]{2}{*}{ Dum 2 (Controlling vs. Neutral) } & -.05 & .14 & -.04 & {$[-.25, .18]$} & -0.33 & .743 \\
\hline & \multicolumn{6}{|c|}{ End-of-day loneliness } \\
\hline (Intercept) & .70 & .17 & .06 & {$[-.13, .24]$} & 4.14 & $<.001$ \\
\hline Pre-solitude loneliness & .60 & .05 & .64 & {$[.54, .74]$} & 13.00 & $<.001$ \\
\hline Dum 1 (Autonomy-supportive vs. Neutral) & -.17 & .16 & -.14 & {$[-.38, .11]$} & -1.08 & .280 \\
\hline \multirow[t]{2}{*}{ Dum 2 (Controlling vs. Neutral) } & -.03 & .16 & -.02 & {$[-.26, .22]$} & -0.20 & .841 \\
\hline & \multicolumn{6}{|c|}{ End-of-day relatedness } \\
\hline (Intercept) & 1.28 & .29 & -.10 & {$[-.27, .08]$} & 4.38 & $<.001$ \\
\hline Pre-solitude relatedness & .75 & .05 & .67 & {$[.57, .76]$} & 14.08 & $<.001$ \\
\hline Dum 1 (Autonomy-supportive vs. Neutral) & .26 & .13 & .24 & {$[-.00, .47]$} & 1.97 & .050 \\
\hline Dum 2 (Controlling vs. Neutral) & .05 & .13 & .04 & {$[-.19, .27]$} & 0.36 & .717 \\
\hline
\end{tabular}




\section{Table 4}

Means and Standard Deviations of Affect Variables, With Cohen's d Effect Sizes Depicting Changes From Prior to After Alone With Thoughts (Study 1)

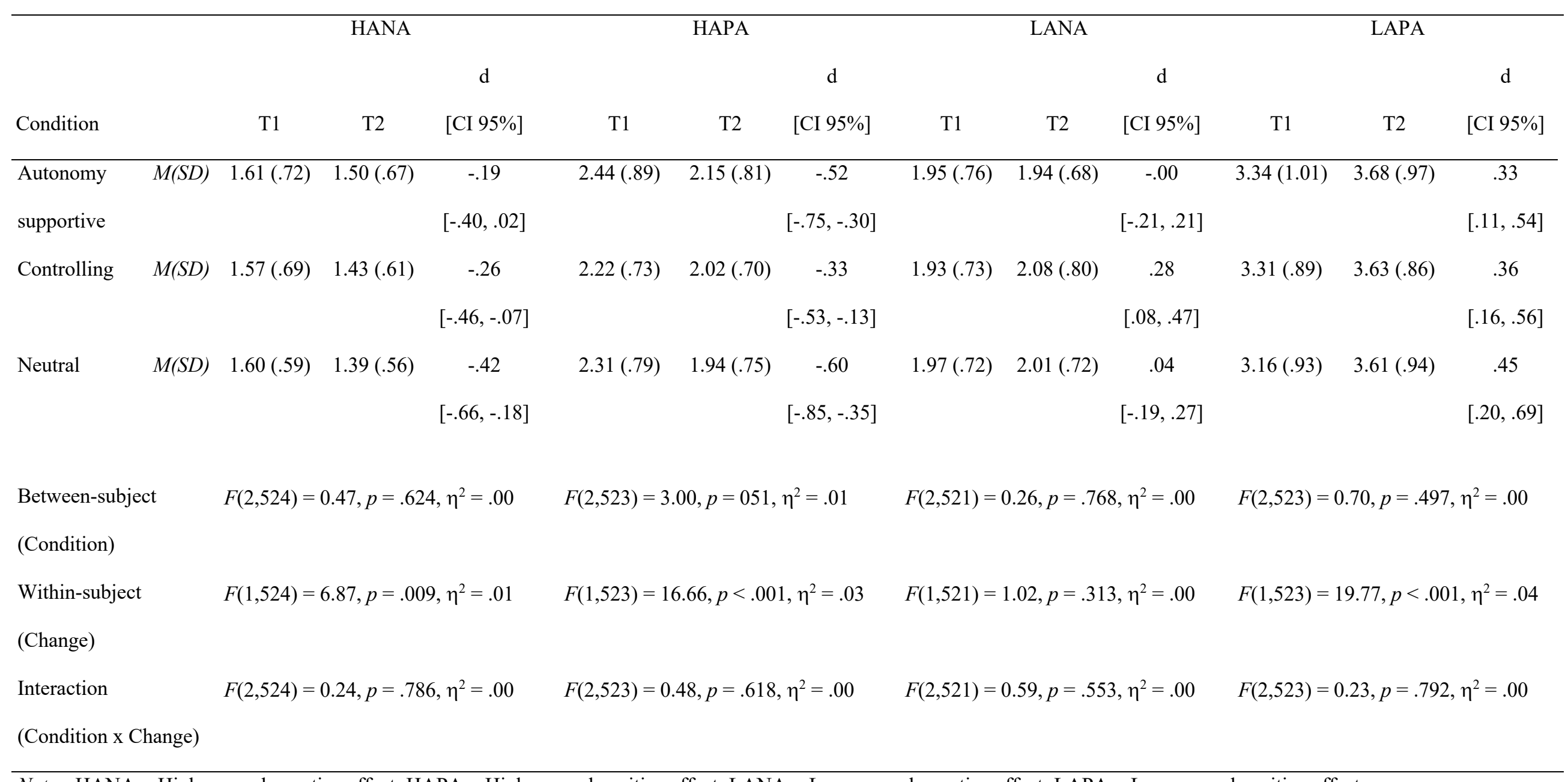

Notes. HANA = High-arousal negative affect; HAPA = High-arousal positive affect; LANA = Low-arousal negative affect; LAPA = Low-arousal positive affect 
Table 5

Means and Standard Deviations of Affect Variables, with Cohen's d Effect Sizes Depicting Changes From Prior to After Alone With Nothing (Study 2)

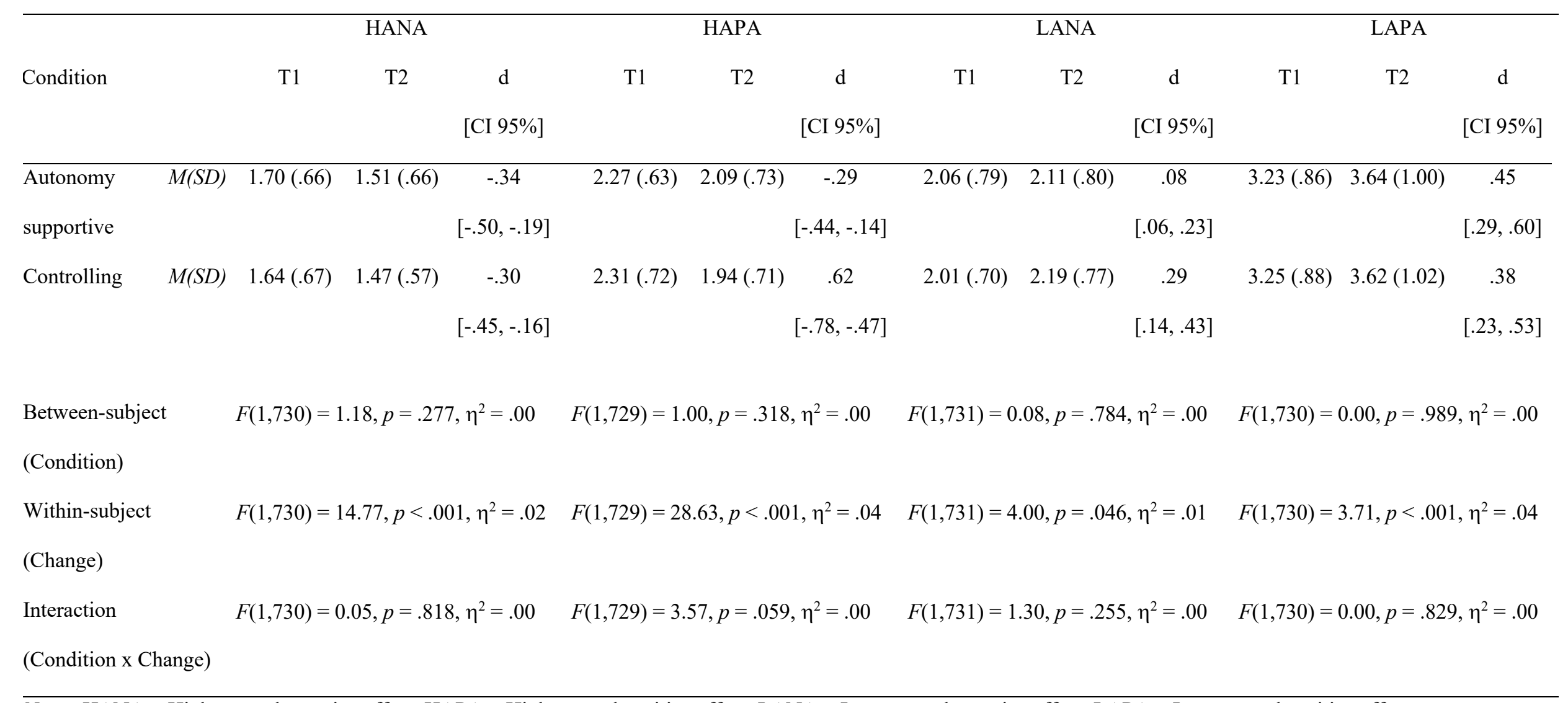

Notes. HANA = High-arousal negative affect; HAPA = High-arousal positive affect; LANA = Low-arousal negative affect; LAPA = Low-arousal positive affect 


\section{Table 6}

Means and Standard Deviations of all Measured Variables, T-tests, Effect Sizes (Study 2)

\begin{tabular}{ccccccccc}
\hline & \multicolumn{3}{c}{$\begin{array}{c}\text { Autonomy } \\
\text { support } \\
(\mathrm{n}=180)\end{array}$} & $\begin{array}{c}\text { Controlling } \\
(\mathrm{n}=189)\end{array}$ & $t$ & $d f$ & $\begin{array}{c}p \text { (one- } \\
\text { tailed) }\end{array}$ & $d$ \\
\hline Perceived autonomy support & $\mathbf{M}$ & 5.81 & 5.01 & 6.28 & 357.73 & $<.001$ & .65 \\
& SD & 1.10 & 1.35 & & & & {$[.44, .86]$} \\
Perceived relatedness support & M & 5.49 & 4.31 & 10.45 & 351.43 & $<.001$ & 1.09 \\
& SD & .95 & 1.20 & & & & {$[.87,1.31]$} \\
Perceived competence support & M & 6.04 & 5.67 & 3.58 & 365.14 & $<.001$ & .37 \\
& SD & .92 & 1.03 & & & & {$[.17, .58]$} \\
Extra pencils during free-choice & M & 197.80 & 215.71 & -1.13 & 359.24 & .257 & -.12 \\
& SD & 151.08 & 149.16 & & & & {$[-.32, .09]$} \\
Enjoy free-choice period & M & 5.92 & 5.84 & 0.54 & 363.74 & .593 & .06 \\
& SD & 1.48 & 1.50 & & & & {$[-.15, .26]$} \\
Enjoyable & M & 5.64 & 5.62 & 0.10 & 364.64 & .920 & .01 \\
& SD & 2.10 & 2.06 & & & & {$[-.19, .21]$} \\
& M & 3.35 & 3.38 & -0.11 & 363.41 & .910 & -.01 \\
& Relaxing & M & 2.19 & 2.15 & & & & {$[-.22, .19]$} \\
& SD & 5.81 & 5.70 & 0.53 & 361.26 & .594 & .06 \\
& & 2.14 & 2.01 & & & & {$[-.15, .26]$} \\
\hline
\end{tabular}




\section{Table 7a}

Regression Analyses Examining the Effects of Autonomy Supportive and Controlling Instructions on Endof-Day Relatedness and Future Engagement With Solitude

\begin{tabular}{|c|c|c|c|c|c|c|}
\hline & $B$ & $S E . B$ & $\beta$ & CI 95\% (及) & $t$ & $p$ \\
\hline & \multicolumn{6}{|c|}{ End-of-day relatedness } \\
\hline (Intercept) & 2.14 & .29 & -.00 & {$[-.09, .09]$} & 7.31 & $<.001$ \\
\hline Pre-solitude relatedness & .63 & .05 & .57 & {$[.48, .66]$} & 12.05 & $<.001$ \\
\hline \multirow[t]{2}{*}{ Autonomy-supportive vs. Controlling } & -.17 & .11 & -.08 & {$[-.17, .02]$} & -1.60 & .110 \\
\hline & \multicolumn{6}{|c|}{ Future Engagement with Solitude } \\
\hline (Intercept) & .96 & .11 & .00 & {$[-.11, .11]$} & 8.72 & $<.001$ \\
\hline Autonomy-supportive vs. Controlling & .15 & .16 & .05 & {$[-.06, .17]$} & .96 & .338 \\
\hline
\end{tabular}

\section{Table 7b}

Chi-square Test Comparing Number of Participants from Autonomy Supportive $(n=$ 151) and Controlling Conditions $(n=156)$ Showing Future Engagement with Solitude Outside of the Lab

\begin{tabular}{lcccc}
\hline & $\begin{array}{c}\text { Did not engage in } \\
\text { solitude }\end{array}$ & $\begin{array}{c}\text { Engaged in } \\
\text { solitude }\end{array}$ & $\chi^{2}$ & $p$ \\
\hline Autonomy supportive & 80 & 71 & 1.37 & .242 \\
Controlling & 94 & 62 & & \\
\hline
\end{tabular}




\section{Figure 1}

Forest Plots Illustrating Cohen's ds, Representing Differences Between Autonomy-Supportive and Controlling-Instruction Conditions on In-Lab

Outcomes in Both Study 1 and Study 2

\section{Study 1}

Autonomy supportive vs. Controlling instructions

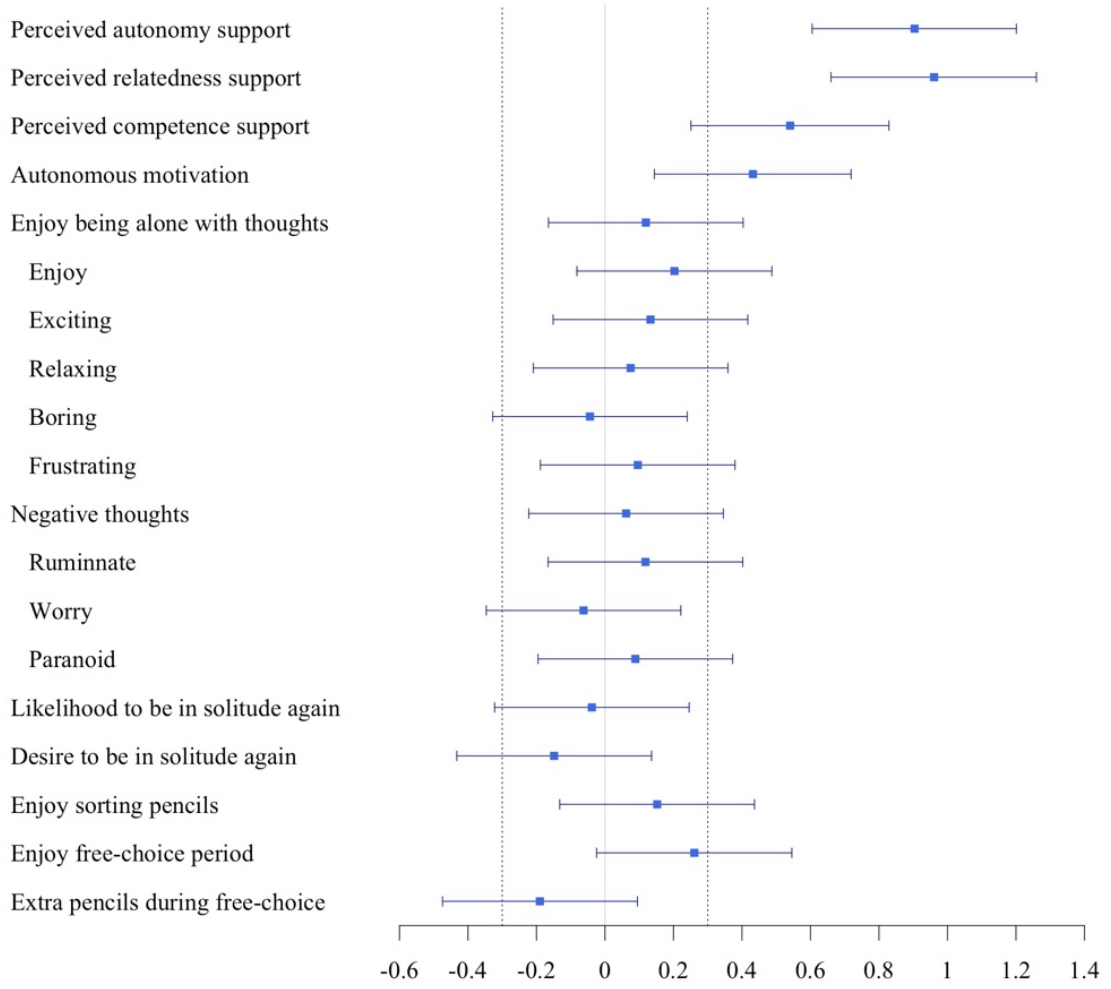

Study 2

Autonomy supportive vs. Controlling instructions

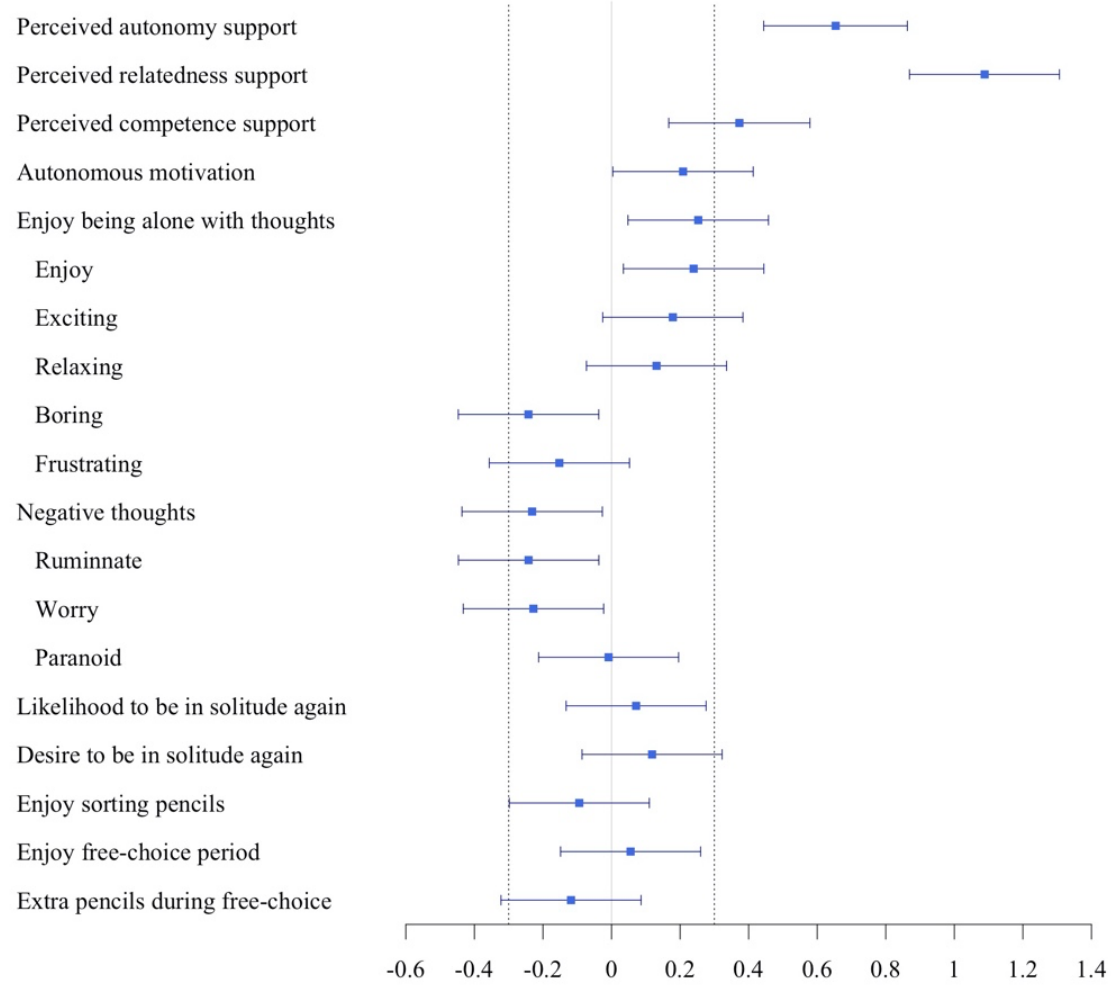

Notes. These forest plots compare the differences between autonomy-supportive and controlling-instruction conditions on in-lab measures against the interval null of -.30 and .30. In these plots, the blue squares represent the standardized differences (Cohen's d) observed in Study 1 and Study 2, with 95\% confidence intervals (CI) around those coefficients. The dotted vertical lines represent the upper and lower bounds of the interval null. The effects that have $95 \%$ CI falling within the interval null were determined too small to be practically meaningful. 
Figure 2

Forest Plots Illustrating Standardized Coefficient $\beta$, Representing Differences Between Pairs of Conditions on End-of-Day Measures in Both

Study 1 and Study 2

\section{STUDY 1}

Effects of Autonomy Supportive vs. Neutral Instructions

$$
\text { on End-of-Day Well-Being }
$$

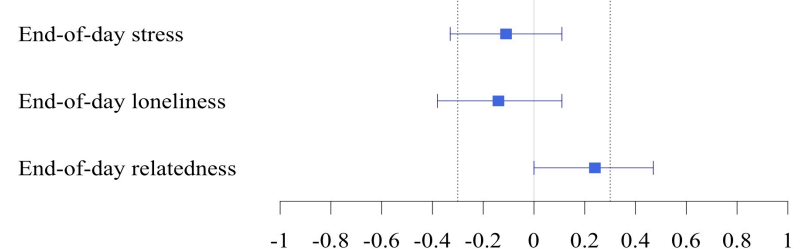

Effects of Controlling vs. Neutral Instructions

on End-of-Day Well-Being

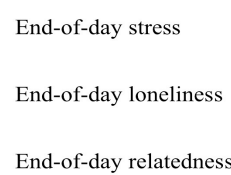

End-of-day relatedness

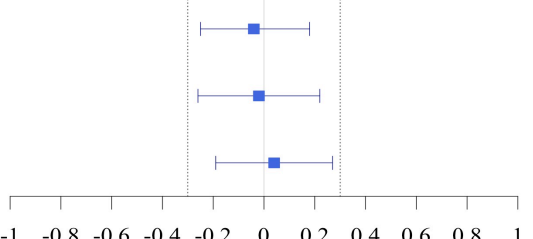

Effects of Autonomy Supportive vs. Controlling Instructions

on End-of-Day Well-Being

\section{End-of-day stress \\ End-of-day loneliness \\ End-of-day relatedness}

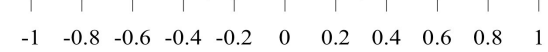

Notes. These forest plots compare the differences between pairs of conditions on end-of-day measures against the interval null of -.30 and .30. In these plots, the blue squares represent the standardized coefficients ( $\beta$ ) observed in Study 1 and Study 2, with 95\% confidence intervals (CI) around those coefficients. The dotted vertical lines represent the upper and lower bounds of the interval null. The effects that have 95\% CI falling within the interval null were determined too small to be practically meaningful.

\section{STUDY 2}

Effects of Autonomy Supportive vs. Controlling Instructions on End-of-Day Measures

End-of-day relatedness

Pursuing solitude outside of lab

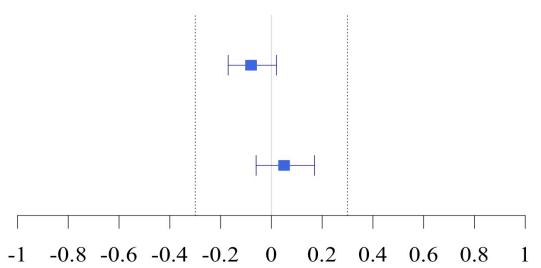




\section{Supplementary Tables}

\section{What are the consistencies in findings between Study 1 and Study 2?}

Below we will report the results of analyses that were not preregistered. In Study 1, we did not find evidence for the condition effects on participants' self-reported experiences with being alone with their thoughts. In Study 2, we found that participants in the autonomy-supportive instruction condition reported greater composite scores of all the items assessing participants' experiences with being alone with thoughts $(M=4.02, S D=1.23)$ than did those in the controllinginstruction condition $(M=3.71, S D=1.21 ; d=.25, \mathrm{CI} 95 \%=[.05, .46])$. Independent $t$-tests on individual items showed only significant effects on two items "enjoyable" $(d=.24$, CI $95 \%=[.03$, $.44], t(363.26)=2.30, p=.022)$, and "boring" $(d=.24$, CI $95 \%=[.04, .45])$. In both cases, autonomy supportive condition scored higher than controlling condition.

We also found a significant difference between autonomy supportive and controlling conditions on composite scores of all items assessing participants' levels of negative thoughts $(d=$ .23 , CI 95\% $=[-.44,-.03])$. Independent $t$-tests predicting individual items showed only significant effects on two items "ruminate" $(d=-.24$, CI 95\% $=[-.45,-.04])$, and "worry" $(d=-.23$, CI 95\% $=$ $[-.43,-.02])$. In both cases, those in the controlling-instruction condition scored higher than did those in the autonomy-supportive instruction condition predicting those negative thought items. These effects were not significant in Study 1.

We did not find significant condition effect on items assessing participant's self-reported intention to experience similar solitude experience again $(d=.07$, CI $95 \%=[-.13, .28])$, or on their desire to do it again $(d=.12$, CI 95\% $=[-.09, .32])$. These findings are consistent with Study 1 where we also did not find significant differences predicting these items. Similarly, participants in autonomy-supportive and controlling-instruction conditions did not show significant difference on their composite scores of all the items assessing participants' experience with the pencil sorting period (see Table S1). 
Table S1

Means and Standard Deviations of all Measured Variables, T-tests, Effect Sizes (Study 2)

\begin{tabular}{|c|c|c|c|c|c|c|c|}
\hline & & $\begin{array}{l}\text { Autonomy } \\
\text { support } \\
(n=180)\end{array}$ & $\begin{array}{l}\text { Controlling } \\
(n=189)\end{array}$ & $t$ & $d f$ & $\begin{array}{l}p \text { (one- } \\
\text { tailed) }\end{array}$ & $d$ \\
\hline \multirow[t]{2}{*}{ Autonomous motivation } & $M$ & 5.06 & 4.86 & 2.00 & 360.99 & .046 & .21 \\
\hline & $S D$ & 0.96 & 1.00 & & & & {$[.00, .41]$} \\
\hline \multirow[t]{2}{*}{ Enjoy being alone with thoughts } & $M$ & 4.42 & 4.11 & 2.43 & 362.16 & .016 & .25 \\
\hline & $S D$ & 1.23 & 1.21 & & & & {$[.05, .46]$} \\
\hline \multirow[t]{2}{*}{ Enjoyable } & $M$ & 4.27 & 3.84 & 2.30 & 363.26 & .022 & .24 \\
\hline & $S D$ & 1.84 & 1.76 & & & & {$[.03, .44]$} \\
\hline \multirow[t]{2}{*}{ Exciting } & $M$ & 2.22 & 1.97 & 1.72 & 357.00 & .087 & .18 \\
\hline & $S D$ & 1.43 & 1.27 & & & & {$[-.03, .38]$} \\
\hline \multirow[t]{2}{*}{ Relaxing } & $M$ & 5.06 & 4.84 & 1.26 & 363.62 & .208 & .13 \\
\hline & $S D$ & 1.69 & 1.66 & & & & {$[-.07, .34]$} \\
\hline \multirow[t]{2}{*}{ Boring } & $M$ & 3.43 & 3.86 & -2.33 & 365.84 & .021 & -.24 \\
\hline & $S D$ & 1.77 & 1.81 & & & & {$[.04, .45]$} \\
\hline \multirow[t]{2}{*}{ Frustrating } & $M$ & 1.98 & 2.20 & -1.46 & 362.46 & .145 & -.15 \\
\hline & $S D$ & 1.31 & 1.54 & & & & {$[-.05, .36]$} \\
\hline \multirow{2}{*}{$\begin{array}{l}\text { Negative thoughts when being } \\
\text { alone with thoughts }\end{array}$} & $M$ & 1.85 & 2.03 & -2.22 & 359.13 & .027 & -.23 \\
\hline & $S D$ & 0.77 & 0.73 & & & & {$[-.44,-.03]$} \\
\hline \multirow[t]{2}{*}{ Ruminate } & $M$ & 2.05 & 2.33 & -2.32 & 362.93 & .021 & -.24 \\
\hline & $S D$ & 1.17 & 1.12 & & & & {$[-.45,-.04]$} \\
\hline \multirow[t]{2}{*}{ Worry } & $M$ & 1.84 & 2.09 & -2.19 & 359.62 & .029 & -.23 \\
\hline & $S D$ & 0.98 & 1.18 & & & & {$[-.43,-.02]$} \\
\hline \multirow[t]{2}{*}{ Paranoid } & $M$ & 1.66 & 1.67 & -.08 & 35.57 & .935 & -.01 \\
\hline & $S D$ & .94 & 0.81 & & & & {$[-.21, .20]$} \\
\hline \multirow[t]{2}{*}{ Likelihood to do it again } & $M$ & 5.02 & 4.84 & .69 & 361.69 & .491 & .07 \\
\hline & $S D$ & 2.37 & 2.55 & & & & {$[-.13, .28]$} \\
\hline \multirow[t]{2}{*}{ Desire to do it again } & $M$ & 5.59 & 5.31 & 1.14 & 364.57 & .256 & .12 \\
\hline & $S D$ & 2.31 & 2.48 & & & & {$[-.09, .32]$} \\
\hline \multirow[t]{2}{*}{ Enjoy sorting pencils } & $M$ & 5.46 & 5.63 & -.90 & 365.98 & .367 & -.09 \\
\hline & $S D$ & 1.69 & 1.77 & & & & {$[-.30, .11]$} \\
\hline
\end{tabular}

Finally, for end-of-day measures, we also did not find significant differences between autonomy-supportive and controlling-instruction conditions on measures of stress $(\beta=-.10, \mathrm{CI} 95 \%$ $=[-.28, .13])$, loneliness $(\beta=-.12$, CI 95\% $=[-.34, .12])$, and relatedness $(\beta=.19$, CI 95\% $=[-.02$, .41]) in Study 1. In Study 2, we also did not find significant differences between the two conditions on measures of relatedness $(\beta=-.08$, CI $95 \%=[-.17, .02])$ and engagement with solitude after the lab $(\beta=.05$, CI 95\% $=[-.06, .17])($ see Table S2). 


\section{Table S2}

Regression Analyses Examining the Effects of Autonomy Supportive and Neutral Instructions on End-of-Day

Well-Being, relative to Controlling Instruction.

$\begin{array}{llllll}B & S E . B & \beta & 95 \% C I(\beta) & t\end{array}$

\begin{tabular}{|c|c|c|c|c|c|c|}
\hline \multirow[b]{2}{*}{ (Intercept) } & \multicolumn{6}{|c|}{ End-of-day stress } \\
\hline & .63 & .18 & .07 & {$[-.12, .15]$} & 3.44 & .001 \\
\hline Pre-solitude stress & .77 & .05 & .04 & {$[.64, .82]$} & 16.78 & $<.001$ \\
\hline Dum 1 (Autonomy-supportive vs. Controlling) & -.10 & .13 & -.10 & {$[-.28, .13]$} & -.75 & .456 \\
\hline \multirow[t]{2}{*}{ Dum 2 (Neutral vs. Controlling) } & .05 & .14 & .11 & {$[-.18 . .25]$} & .33 & .743 \\
\hline & \multicolumn{6}{|c|}{ End-of-day loneliness } \\
\hline (Intercept) & .67 & .16 & .08 & {$[-.13, .19]$} & 4.20 & $<.001$ \\
\hline Pre-solitude loneliness & .60 & .05 & .05 & {$[.54, .74]$} & 13.00 & $<.001$ \\
\hline Dum 1 (Autonomy-supportive vs. Controlling) & -.14 & .15 & -.12 & {$[-.34, .12]$} & -.95 & .341 \\
\hline \multirow[t]{2}{*}{ Dum 2 (Neutral vs. Controlling) } & .03 & .16 & .12 & {$[-.22, .26]$} & .20 & .841 \\
\hline & \multicolumn{6}{|c|}{ End-of-day relatedness } \\
\hline (Intercept) & 1.32 & .30 & -.05 & {$[-.20, .10]$} & 4.48 & $<.001$ \\
\hline Pre-solitude relatedness & .75 & .05 & .67 & {$[.57, .76]$} & 14.08 & $<.001$ \\
\hline Dum 1 (Autonomy-supportive vs. Controlling) & .22 & .12 & .19 & {$[-.02, .41]$} & 1.75 & .082 \\
\hline Dum 2 (Neutral vs. Controlling) & -.05 & .13 & -.04 & {$[-.27, .19]$} & -.36 & .717 \\
\hline
\end{tabular}

\section{Could it be there were no condition effects because the pencil task was in fact interesting?}

We did not observe significant differences between conditions predicting the number of pencils sorted during the free-choice period in either study. One possible explanation is that the pencil-sorting task might not have been perceived as unpleasant or banal. We investigated this explanation by comparing participants' ratings of their experiences when sitting alone with thoughts versus when sorting pencils. We conducted a mixed 2 (between-subject: condition) x 2 (withinsubject: experience; alone with thoughts vs. pencil-sorting) ANOVA, with task experience defined 
as the outcome variable. Because task experiences measured after being alone with thoughts and after pencil-sorting are on different Likert-style scales, we converted both variables to $z$ scores.

\section{Table S3}

Means (z scores) and Standard Deviations of Task Experiences, with Cohen's d Effect Sizes Depicting Differences Between Sitting Alone with Thoughts Versus Sorting Pencils

\begin{tabular}{|c|c|c|c|c|c|c|}
\hline \multirow[b]{2}{*}{ Condition } & \multicolumn{3}{|c|}{ Study 1} & \multicolumn{3}{|c|}{ Study 2} \\
\hline & Alone & Pencil & $\begin{array}{c}\mathrm{d} \\
{[\mathrm{CI} 95 \%]}\end{array}$ & Alone & Pencil & $\begin{array}{c}\mathrm{d} \\
\text { [CI 95\%] }\end{array}$ \\
\hline Autonomy supportive & $.07(1.00)$ & $.09(1.04)$ & $\begin{array}{c}-.02 \\
{[-.22, .20]}\end{array}$ & $.13(1.00)$ & $-.05(.98)$ & $\begin{array}{c}.14 \\
{[-.01, .29]}\end{array}$ \\
\hline Controlling & $-.01(.99)$ & $-.02(.95)$ & $\begin{array}{c}-.00 \\
{[-.23, .23]}\end{array}$ & $-.12(.99)$ & $.05(1.02)$ & $\begin{array}{c}-.13 \\
{[-.27, .02]}\end{array}$ \\
\hline Neutral & $-.05(1.02)$ & $-.06(1.00)$ & $\begin{array}{c}.02 \\
{[-.17, .21]}\end{array}$ & & & \\
\hline Between-subject (Condition) & \multicolumn{3}{|c|}{$F(2,521)=0.92, p=.397, \eta^{2}=.00$} & \multicolumn{3}{|c|}{$F(1,729)=1.14, p=.286, \eta^{2}=.00$} \\
\hline Within-subject (Experience) & \multicolumn{3}{|c|}{$F(1,521)=0.00, p=.995, \eta^{2}=.00$} & \multicolumn{3}{|c|}{$F(1,729)=0.00, p=.997, \eta^{2}=.00$} \\
\hline $\begin{array}{l}\text { Interaction } \\
\text { (Condition x Experience) }\end{array}$ & \multicolumn{3}{|c|}{$F(2,521)=0.02, p=.983, \eta^{2}=.00$} & \multicolumn{3}{|c|}{$F(2,729)=5.54, p=.019, \eta^{2}=.01$} \\
\hline
\end{tabular}

Data from Study 1 did not yield significant main effects nor interaction. These was no evidence that participants perceived the two experiences as qualitatively different, nor did they perceive the two experiences differently across the three conditions (i.e., autonomy supportive, neutral, controlling). Data from Study 2 yielded one significant interaction but no main effects. Participants in the autonomy-supportive condition found sitting alone with thoughts relatively more enjoyable than sorting pencils $(d=.14$, CI $95 \%=[-.01, .29])$ whereas those in the controlling condition found sorting pencils more enjoyable $(d=-.13$, CI 95\% $=[-.27, .02])$. However, the size of this interaction effect was minimal and both Cohen's $d$ s did not surpass the smallest effect size that our sample had adequate power to detect. Therefore, we did not find any evidence that participants felt the pencil-sorting experience any more or less enjoyable than sitting alone with thoughts. This finding suggests to us that the pencil-sorting task was a comparable alternative that was appropriate for us to test our hypothesis of whether participants would prefer another unpleasant alternative to sitting alone with thought. 